University of Wollongong

Research Online

Australian Institute for Innovative Materials -

Papers

Australian Institute for Innovative Materials

$1-1-2018$

Synergistic Amplification of Water Oxidation Catalysis on Pt by a Thin-Film Conducting Polymer Composite

\author{
Mohammed Alsultan \\ University of Wollongong, mfka287@uowmail.edu.au \\ Sivakumar Balakrishnan \\ University of Wollongong \\ Jaecheol Choi \\ University of Wollongong, jc878@uowmail.edu.au \\ Rouhollah Jalili \\ University of Wollongong, rjalili@uow.edu.au \\ Prerna Tiwari \\ University of Wollongong, pt832@uowmail.edu.au
}

See next page for additional authors

Follow this and additional works at: https://ro.uow.edu.au/aiimpapers

Part of the Engineering Commons, and the Physical Sciences and Mathematics Commons

Research Online is the open access institutional repository for the University of Wollongong. For further information contact the UOW Library: research-pubs@uow.edu.au 


\title{
Synergistic Amplification of Water Oxidation Catalysis on Pt by a Thin-Film Conducting Polymer Composite
}

\author{
Abstract \\ Despite their potential for facilitating high activity, thin-film conducting polymer supports have, historically, \\ expedited only relatively weak performances in catalytic water oxidation (with current densities in the $\mu \mathrm{A} /$ \\ $\mathrm{cm} 2$ range). In this work, we have investigated the conditions under which thin-film conducting polymers \\ may synergistically amplify catalysis. A composite conducting polymer film has been developed that, \\ when overcoated on a bare Pt electrode, amplifies its catalytic performance by an order of magnitude \\ (into the $\mathrm{mA} / \mathrm{cm} 2$ range). When poised at $0.80 \mathrm{~V}(\mathrm{vs} \mathrm{Ag} / \mathrm{AgCl})$ at $\mathrm{pH} 12$, a control, bare Pt electrode \\ yielded a current density of $0.15 \mathrm{~mA} / \mathrm{cm} 2$ for catalytic water oxidation. When then overcoated with a \\ composite poly(3,4-ethylenedioxythiophene) (PEDOT) film containing nanoparticulate $\mathrm{Ni}$ (nano-Ni) \\ catalyst and reduced graphene oxide (rGO) conductor in the specific molar ratio of 4.5 (C; PEDOT): 1 (Ni): \\ 9.5 (C; other), the electrode generated water oxidation current densities of $1.10-1.15 \mathrm{~mA} / \mathrm{cm} 2$ under the \\ same conditions (over $>50 \mathrm{~h}$ of operation; including a photocurrent of $0.55 \mathrm{~mA} / \mathrm{cm} 2$ under light \\ illumination of 0.25 sun). Control films containing other combinations of the above components, yielded \\ notably lower currents. These conditions represent the most favorable for water oxidation at which \\ PEDOT does not degrade. Studies suggested that the above composite contained an optimum ratio of \\ catalyst density to conductivity and thickness in which the PEDOT electrically connected the largest \\ number of catalytic sites (thereby maximizing the catalytically active area) by the shortest, least-resistive \\ pathway (thereby minimizing the Tafel slope). That is, the amplification appeared to be created by a \\ synergistic matching of the connectivity, conductivity, and catalytic capacity of the film. This approach \\ provides a potential means for more effectively deploying thin-film conducting polymers as catalyst \\ supports.

\section{Disciplines} \\ Engineering | Physical Sciences and Mathematics

\section{Publication Details} \\ Alsultan, M., Balakrishnan, S., Choi, J., Jalili, R., Tiwari, P., Wagner, P. \& Swiegers, G. F. (2018). Synergistic \\ Amplification of Water Oxidation Catalysis on Pt by a Thin-Film Conducting Polymer Composite. ACS \\ Applied Energy Materials, 1 (8), 4235-4246.

\section{Authors} \\ Mohammed Alsultan, Sivakumar Balakrishnan, Jaecheol Choi, Rouhollah Jalili, Prerna Tiwari, Pawel W. \\ Wagner, and Gerhard F. Swiegers
}




\section{Synergistic Amplification of Water Oxidation}

\section{Catalysis on Pt by a Thin-Film Conducting Polymer}

\section{Composite}

Mohammed Alsultan, ${ }^{a, b}$ Sivakumar Balakrishnan, ${ }^{a}$ Jaecheol Choi, ${ }^{a}$ Rouhollah Jalili, ${ }^{a}$ Prerna Tiwari, Pawel Wagner, ${ }^{a}$ Gerhard F. Swiegers ${ }^{a, *}$

a Intelligent Polymer Research Institute, University of Wollongong, Wollongong, NSW 2522, Australia and ARC Centre of Excellence for Electromaterials Science, University of Wollongong, Wollongong, NSW 2522, Australia

${ }^{\mathrm{b}}$ College of Science, University of Mosul, Mosul, Iraq

KEYWORDS: PEDOT, water oxidation, catalyst, photocatalyst, oxygen

ABSTRACT: Despite their potential for facilitating high activity, thin-film conducting polymer supports have, historically, expedited only relatively weak performances in catalytic water oxidation (with current densities in the $\mu \mathrm{A} / \mathrm{cm}^{2}$ range). In this work we have investigated the conditions under which thin-film conducting polymers may synergistically amplify catalysis. A composite conducting polymer film has been developed that, when overcoated on a bare Pt electrode, amplifies its catalytic performance by an order of magnitude (into the $\mathrm{mA} / \mathrm{cm}^{2}$ range). When poised at $0.80 \mathrm{~V}$ (vs $\mathrm{Ag} / \mathrm{AgCl})$ at $\mathrm{pH} 12$, a control, bare Pt electrode yielded a current 
density of $0.15 \mathrm{~mA} / \mathrm{cm}^{2}$ for catalytic water oxidation. When then overcoated with a composite poly(3,4-ethylenedioxythiophene) (PEDOT) film containing nanoparticulate $\mathrm{Ni}$ ('nano-Ni') catalyst and reduced graphene oxide (rGO) conductor in the specific molar ratio of 4.5 (C; PEDOT) : 1 (Ni) : 9.5 (C; other), the electrode generated water oxidation current densities of 1.10-1.15 $\mathrm{mA} / \mathrm{cm}^{2}$ under the same conditions (over $>50 \mathrm{~h}$ of operation; including a photocurrent of $0.55 \mathrm{~mA} / \mathrm{cm}^{2}$ under light illumination of 0.25 sun). Control films containing other combinations of the above components, yielded notably lower currents. These conditions represent the most favorable for water oxidation at which PEDOT does not degrade. Studies suggested that the above composite contained an optimum ratio of catalyst density to conductivity and thickness in which the PEDOT electrically connected the largest number of catalytic sites (thereby maximizing the catalytically active area) by the shortest, least-resistive pathway (thereby minimizing the Tafel slope). That is, the amplification appeared to be created by a synergistic matching of the connectivity, conductivity, and catalytic capacity of the film. This approach provides a potential means for more effectively deploying thin-film conducting polymers as catalyst supports.

\section{INTRODUCTION}

Thin film conducting polymers (CP) have recently gained attention as potentially useful substrates for immobilizing water oxidation catalysts, particularly solar-assisted or solardriven catalysts. ${ }^{1}$ For example, the conducting polymer poly(terthiophene), incorporating Mn porphyrins, has been demonstrated to display the very useful property that it selectively splits seawater into pure oxygen only, with no measurable chlorine formation

detected. $^{2,3}$ In common with several other systems involving thin-film conducting 
polymer substrates however, the catalysis was only weakly active, achieving current densities in the low $\mu \mathrm{A} / \mathrm{cm}^{2}$ range. ${ }^{1-3}$

Water oxidation is an uphill chemical reaction that requires an electrochemical cell potential of at least $1.23 \mathrm{~V}$. In practice, higher potentials must be applied due to the overpotential of the oxygen evolution reaction (OER). ${ }^{4}$ At a particular $\mathrm{pH},{ }^{5}$ the activity of water oxidation electrocatalysts typically depend on the active area involved, ${ }^{6}$ the electrical resistance of the conduction pathway to the electrode surface, and the external bias that is applied. ${ }^{7}$ Sunlight may also be harnessed if the materials employed have wide visible absorption bands. ${ }^{8-10}$

Conducting polymers have the potential - at least in theory - to mediate all of the above properties and thereby strongly assist the catalytic process. However, that potential has remained largely unrealised with conducting polymer substrates appearing to mostly restrain and not maximally facilitate catalytic processes. ${ }^{1} \mathrm{~A}$ key challenge in this respect is to understand how to fabricate conducting polymer supports in a form that promotes the highest possible catalytic activity. At present, only very general guidelines are available. ${ }^{1}$

A case in point is poly(3,4-ethylenedioxythiophene) (PEDOT), which is widely considered to be the best available conducting polymer in terms of its conductivity, processability, transparency to visible light, stability, and capacity for fast electrochemical switching. ${ }^{11}$ Several studies have examined PEDOT within oxygen-generating electrodes. ${ }^{2,3,12-14}$ However, its performance in such systems has generally been poor, being apparently hampered by a relatively low intrinsic conductivity and catalytic capacity, even at its maximum bias of $0.8 \mathrm{~V}$ (vs $\mathrm{Ag} / \mathrm{AgCl}$ ) and $\mathrm{pH}$ of $12 .^{1-3}$ At higher voltages and pHs, PEDOT may be susceptible to degradative over-oxidation. 
To more fully understand what is needed in PEDOT thin-films, we were interested to see whether such supports could be induced to produce synergistic amplifications of catalytic performance. That is, whether a PEDOT support could accelerate a catalytic effect beyond what may be expected from the catalyst alone and, if so, how much? To test this concept we fabricated and studied composites of PEDOT that incorporated known, active OER catalysts (to boost catalytic performance) ${ }^{15}$ and suitable conducting materials (to augment conductivity). We further varied the ratios of the components.

In this work we describe studies of uniformly deposited PEDOT composites containing nanoparticulate $\mathrm{Ni}$ ('nano-Ni') (av. diameter: $20 \mathrm{~nm}$ ) as an active OER catalyst and partially reduced graphene oxide ('rGO') as a conductor. While graphene oxide (GO) is hydrophilic ${ }^{16,17}$ and insulating, ${ }^{18}$ it is more conducting in its reduced, rGO form. ${ }^{19-21}$ Additionally, rGO has potential in OER catalysis ${ }^{22-28}$ (and other forms of catalysis). ${ }^{29}$

We report that thin-film composites containing specific ratios of the above components display synergistically amplified ${ }^{22,30-32}$ OER photoelectrocatalysis. Moreover, the catalytic performance of a thin film of PEDOT : nano-Ni : rGO having a molar ratio of $4.5(\mathrm{C}$; PEDOT) : 1 (Ni) : 9.5 (C; other) significantly superseded that of other combinations. It also superseded the performance of Pt, the industry-standard, benchmark OER electrocatalyst. When poised at $0.80 \mathrm{~V}$ (vs $\mathrm{Ag} / \mathrm{AgCl})$ in $\mathrm{pH} 12$ solution, a Pt electrode yielded $0.15 \mathrm{~mA} / \mathrm{cm}^{2}$. When then overcoated with the above PEDOT/nano$\mathrm{Ni} / \mathrm{rGO}$ composite, the Pt produced an order-of-magnitude greater current of 1.10-1.15 $\mathrm{mA} / \mathrm{cm}^{2}$ under the same conditions (including a photocurrent of $0.55 \mathrm{~mA} / \mathrm{cm}^{2}$ under 0.25 sun illumination). Studies suggested that the above composite contained an optimum ratio of catalyst density to conductivity and thickness in which the PEDOT electrically 
connected the largest number of catalytic sites (thereby maximizing the catalytically active area) by the shortest, least-resistive pathway (thereby minimizing the Tafel slope). The resulting synergistic matching of the electrical connectivity and conductivity with the catalytic capacity induced the amplified catalytic performance. This approach potentially offers a means of maximizing the effectiveness of thin-film conducting polymers as catalyst supports.

\section{RESULTS AND DISCUSSION}

2.1 Studies of PEDOT/nano-Ni on FTO. In the first stage of this study, we examined uniformly deposited thin-films of vapour-phase polymerized PEDOT containing varying quantities of nano-Ni (av. $20 \mathrm{~nm}$ diameter) on FTO glass slides $\left(4.2 \mathrm{~cm}^{2}\right)$. On the basis of previous work, ${ }^{2,3}$ the films were tested as water oxidation electro- and/or photo-catalysts in $0.2 \mathrm{M} \mathrm{Na}_{2} \mathrm{SO}_{4}$ aqueous solution, with the $\mathrm{pH}$ adjusted to 12 , while biased at $0.8 \mathrm{~V}$ (vs $\mathrm{Ag} / \mathrm{AgCl})$. These voltage and $\mathrm{pH}$ conditions provide the most favourable settings for OER catalysis under which PEDOT can be safely tested without risking oxidative damage., ${ }^{2,3}$ The standard potential for water oxidation at $\mathrm{pH} 0$ is $1.23 \mathrm{~V}$ vs. standard hydrogen electrode (SHE). However, at $\mathrm{pH} 12$ the minimum theoretical potential is $0.52 \mathrm{~V}$ vs. SHE, which equates to $0.29 \mathrm{~V}$ vs $\mathrm{Ag} / \mathrm{AgCl}$. The testing was carried out with and without light illumination from a SoLux daylight MR16 halogen light bulb ( 0.25 sun intensity).

Figure 1 depicts representative data from this study. As can be seen, increases in the relative quantity of nano-Ni initially led to higher dark currents, as well as higher photocurrents. Thus, a control PEDOT film with no nano-Ni, exhibited tiny currents (Figure 1(a)), whereas films prepared from polymerisation mixtures containing $20 \mathrm{mg}$ 


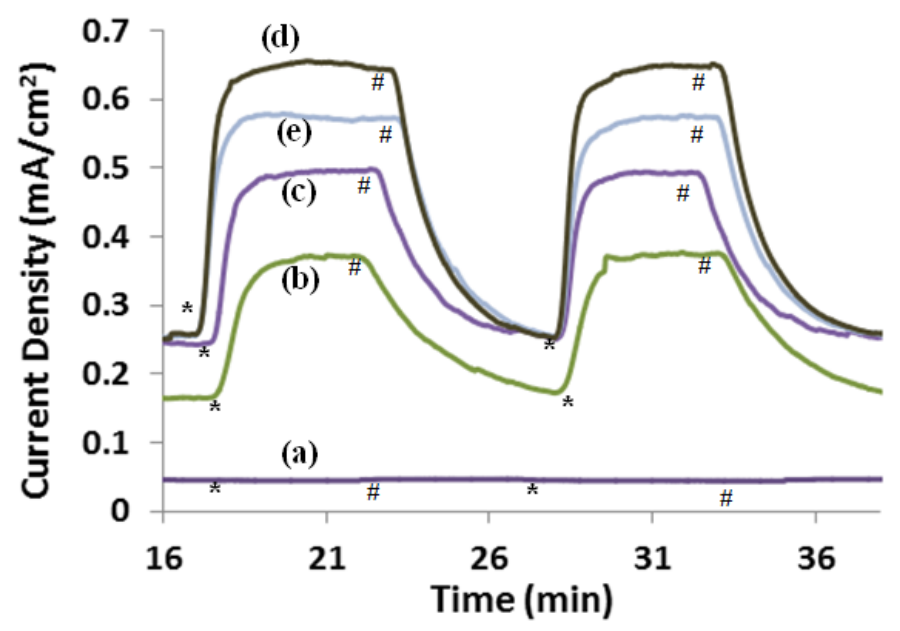

Figure 1. Chronoamperograms at $0.8 \mathrm{~V}$ (vs. $\mathrm{Ag} / \mathrm{AgCl}$ ) in $0.2 \mathrm{M} \mathrm{Na}_{2} \mathrm{SO}_{4}(\mathrm{pH} 12)$, with and without light illumination (0.25 sun), of FTO glass slides coated with: PEDOT/Nano$\mathrm{Ni}$, where the quantity of nano-Ni in the vapour phase polymerisation solution was: (a) 0 mg nano-Ni (PEDOT only; control), (b) 20 mg nano-Ni, (c) 100 mg nano-Ni, (d) 125 mg nano-Ni, and (e) 135 mg nano-Ni. (*='light on', \#='light off').

nano-Ni (Figure 1(b)), 100 mg nano-Ni (Figure 1(c)), or 125 mg nano-Ni (Figure 1(d)) produced ever higher dark currents $\left(0.15-0.25 \mathrm{~mA} / \mathrm{cm}^{2}\right.$ respectively) and photocurrents (0.20-0.40 mA $/ \mathrm{cm}^{2}$ respectively). However, the net current declined when more than 125 mg nano-Ni was incorporated into the films. For example, PEDOT containing $135 \mathrm{mg}$ nano-Ni (Figure 1(e)) produced an unchanged dark current of $\sim 0.25 \mathrm{~mA} / \mathrm{cm}^{2}$ but a lower photocurrent of only $\sim 0.30 \mathrm{~mA} / \mathrm{cm}^{2}$. The additional nano-Ni clearly decreased light absorption by the film.

On this basis, PEDOT/nano-Ni films containing $125 \mathrm{mg}$ of nano-Ni produced the greatest catalytic effect. Further studies examined the incorporation of rGO into this film. The rGO was prepared as described in the Experimental Section. 
2.2 Studies of PEDOT/nano-Ni/rGO on FTO. In the second stage of the study, we prepared and tested thin-films of PEDOT/nano-Ni/rGO on FTO glass in which the polymerisation mixture contained $125 \mathrm{mg}$ of nano-Ni and varying weights of rGO. For these experiments, $\mathrm{GO}$ was synthesized in sulfuric acid using an excess of $\mathrm{KMnO}_{4}$. The GO was then incorporated into the polymerisation mix. The maximum amount of GO that could be incorporated in the films using the vapour phase polymerisation technique was 6 mg. Beyond this level, the polymerisation mixtures became too thick to spin-coat successfully. Immediately prior to testing as a (photo)electrocatalyst, the GO in the films was reduced electrochemically to rGO using cyclic voltammetry (performed in $0.2 \mathrm{M}$ $\mathrm{Na}_{2} \mathrm{SO}_{4}$ (pH 12); 5 cycles between $-1.2 \mathrm{~V}$ and $0.8 \mathrm{~V}$, vs. Ag/AgCl, at $50 \mathrm{mV} / \mathrm{s}$ scan

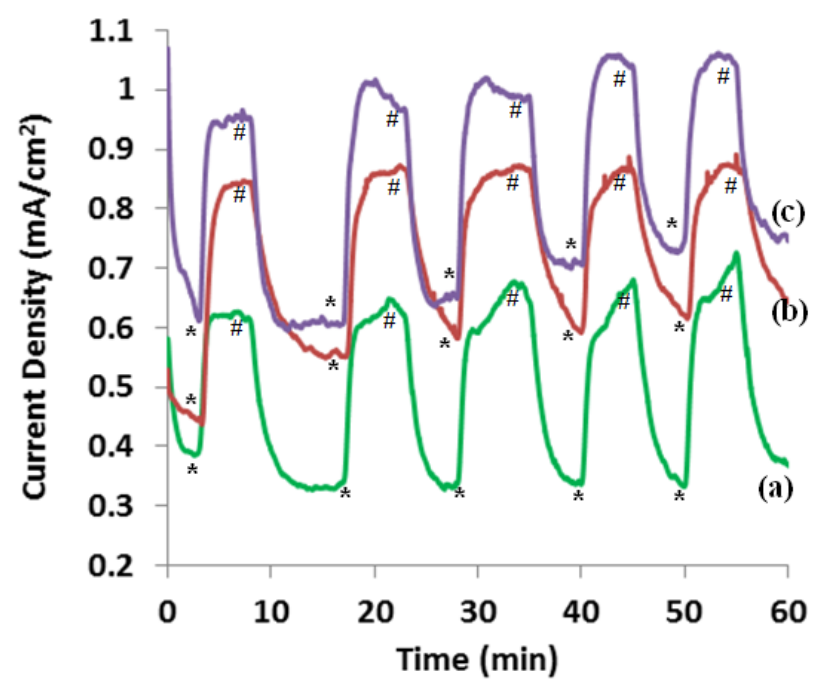

Figure 2. Chronoamperograms at $0.80 \mathrm{~V}$ (vs Ag/AgCl) in $0.2 \mathrm{M} \mathrm{Na}_{2} \mathrm{SO}_{4}(\mathrm{pH} 12)$ over 1 h of operation, with and without light illumination (0.25 sun), of FTO glass slides coated with thin films of PEDOT/nano-Ni/rGO, where the polymerisation mixtures contained $125 \mathrm{mg}$ of nano-Ni and the following quantities of rGO: (a) $4.8 \mathrm{mg}$, (b) $5.4 \mathrm{mg}$, and (c) $6.0 \mathrm{mg}$. (*='light on', \#='light off'). 


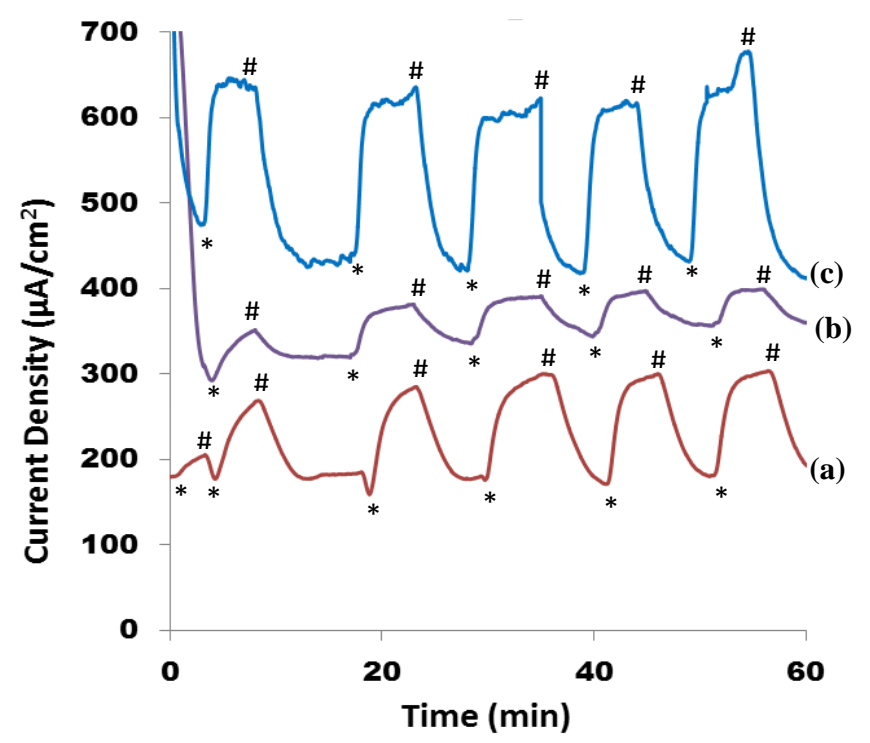

Figure 3. Chronoamperograms at $0.80 \mathrm{~V}$ (vs Ag/AgCl) in $0.2 \mathrm{M} \mathrm{Na}_{2} \mathrm{SO}_{4}(\mathrm{pH} 12)$ over 1 h of operation, with and without light illumination (0.25 sun), of FTO glass slides coated with thin films comprising of: (a) $6.0 \mathrm{mg}$ rGO only, (b) PEDOT containing $6.0 \mathrm{mg}$ rGO, and (c) $125 \mathrm{mg}$ nano-Ni and $6.0 \mathrm{mg}$ rGO (without any PEDOT). (*='light on', \#='light off').

speed). The average charge transferred during the reduction process was $1.6 \mu \mathrm{C}$, consistent with a partial reduction.

Figure 2 depicts chronoamperograms of the best performing of the resulting PEDOT/nano-Ni/rGO films, on FTO glass, at $0.80 \mathrm{~V}$ (vs Ag/AgCl) in $0.2 \mathrm{M} \mathrm{Na}_{2} \mathrm{SO}_{4}(\mathrm{pH}$ 12) over $1 \mathrm{~h}$ of operation, with and without light illumination (0.25 sun).

A systematic increase in the dark currents and photocurrents with increasing rGO loading was observed (Figure 2(a)-(c)). The largest dark current $\left(0.6-0.7 \mathrm{~mA} / \mathrm{cm}^{2}\right)$ and photocurrent $\left(0.30-0.35 \mathrm{~mA} / \mathrm{cm}^{2}\right)$ was produced by PEDOT/nano-Ni/rGO containing 125 mg nano-Ni and $6.0 \mathrm{mg}$ rGO. This film was typically $0.62 \mu \mathrm{m}$ thick and exhibited a conductivity of $8.56 \mathrm{~S} / \mathrm{cm}$ (when prepared and tested on a glass slide). 


\subsection{Studies of Control Films on FTO; Catalytic Amplification due to the PEDOT.}

To assess the influence of the rGO component on the catalytic performance of the above film, we prepared and tested control films containing: (i) $6.0 \mathrm{mg}$ of rGO alone (Figure 3(a)), (ii) PEDOT containing $6.0 \mathrm{mg}$ rGO (Figure 3(b)), and (iii) $6.0 \mathrm{mg}$ rGO and $125 \mathrm{mg}$ nano-Ni only, with no PEDOT present (Figure 3(c)). As the nano-Ni would not adhere to the FTO without a binder, a control thin-film of nano-Ni only could not be prepared.

As can be seen in Figure 3, all of these control films produced notably smaller dark currents and photocurrents than the PEDOT/nano-Ni/rGO film containing 125 mg nano$\mathrm{Ni}$ and $6.0 \mathrm{mg}$ rGO (Figure 2(c)). For example, the best performing control film, which comprised of $6.0 \mathrm{mg}$ rGO and $125 \mathrm{mg}$ nano-Ni only, without any PEDOT present (Figure 3(c)), yielded a dark current that was $\sim 0.2 \mathrm{~mA} / \mathrm{cm}^{2}$ lower and a photocurrent that was $\sim 0.15 \mathrm{~mA} / \mathrm{cm}^{2}$ lower than the above PEDOT/nano-Ni/rGO film.

These combined differences therefore represent a net catalytic amplification (of $\sim 0.35$ $\mathrm{mA} / \mathrm{cm}^{2}$ ) that was created by the presence of the PEDOT in the above PEDOT/nano$\mathrm{Ni} / \mathrm{rGO}$ film. This amplification is substantial, being at least $50 \%$ of the combined dark current and photocurrent of the control film (Figure 3(c)).

It is also noteworthy that this amplification was finely dependent on the precise composition of the PEDOT/nano-Ni/rGO film, since, as demonstrated in Figures 1 and 2, even small changes in the quantities of nano-Ni or rGO present lead to substantial declines in the dark and photocurrents. That is, the observed amplification appeared to be synergistic in that it was dependent on the exact proportions of the components in the PEDOT/nano-Ni/rGO composite. 


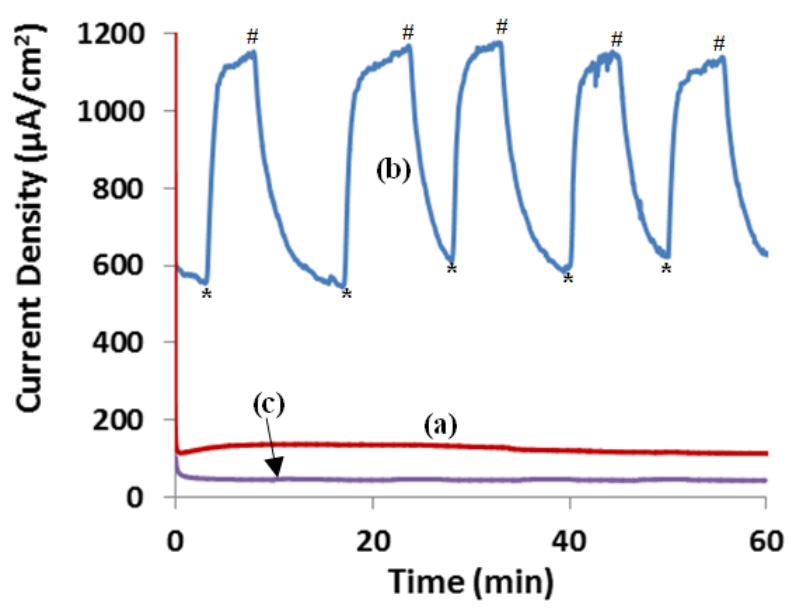

Figure 4. Chronoamperograms at $0.80 \mathrm{~V}$ (vs Ag/AgCl) in $0.2 \mathrm{M} \mathrm{Na}_{2} \mathrm{SO}_{4}(\mathrm{pH} 12)$ over 1 h of operation, with and without light illumination (0.25 sun), of FTO glass slides coated with thin films of: (a) bare Pt, (b) Pt overcoated with PEDOT/nano-Ni/rGO, where the polymerisation mixture contained $125 \mathrm{mg}$ of nano-Ni and $6 \mathrm{mg}$ of rGO, and (c) PEDOT only (control). (*='light on', \#='light off').

2.4 Comparative Studies with Pt. While numerous OER catalysts have been examined at pHs above $13,{ }^{22-28}$ studies against which we could compare the above data, at pH 12, did not appear to be available. A comparison was therefore made with the standard industry OER catalyst, Pt. To that end, a FTO slide was sputter-coated with Pt (100 nm) and tested it under the same conditions. Figure 4(a) shows the result. As can be seen, the freshly-prepared bare Pt electrode generated a steady current over 1 h of $\sim 150 \mu \mathrm{A} / \mathrm{cm}^{2}$. This was substantially less than the best performing PEDOT/nano-Ni/rGO thin film.

To properly compare the two, we overcoated a freshly-prepared Pt-coated FTO slide with a thin film of PEDOT/nano-Ni/rGO containing $125 \mathrm{mg}$ of nano-Ni and $6 \mathrm{mg}$ of rGO. The resulting PEDOT/nano-Ni/rGO on Pt/FTO produced dark currents of $0.55-0.60$ $\mathrm{mA} / \mathrm{cm}^{2}$ and photocurrents of $0.55 \mathrm{~mA} / \mathrm{cm}^{2}$, to give a total current of $1.10-1.15 \mathrm{~mA} / \mathrm{cm}^{2}$ 


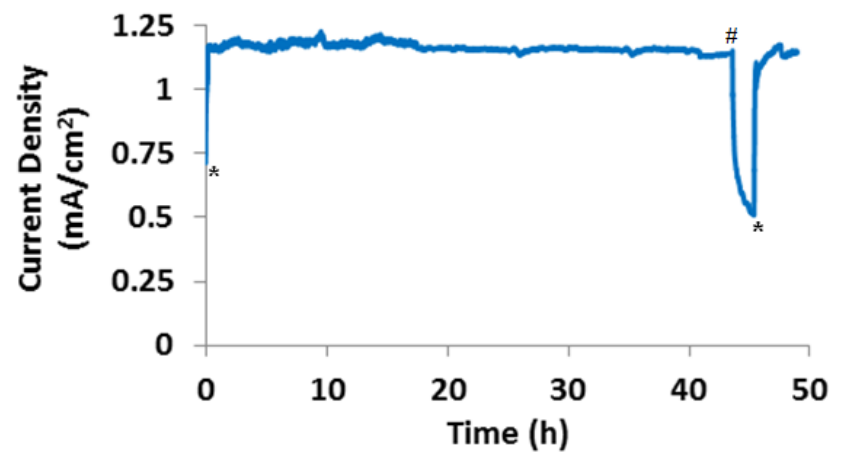

Figure 5. Chronoamperogram at $0.80 \mathrm{~V}$ (vs $\mathrm{Ag} / \mathrm{AgCl}$ ) in $0.2 \mathrm{M} \mathrm{Na}_{2} \mathrm{SO}_{4}(\mathrm{pH} 12)$ over 50 h of operation, with and without light illumination (0.25 sun), of an FTO glass slide coated with a thin film of Pt overcoated with PEDOT/nano-Ni/rGO containing $125 \mathrm{mg}$ nano-Ni and 6 mg rGO (*='light on', \#='light off).

(Figure 4(b)). This was far in excess of the currents generated by the bare Pt film. It was also larger than the equivalent currents of the PEDOT/nano-Ni/rGO on FTO alone (Figure 2(c)). This can be ascribed to the lower sheet resistance arising from the more conductive metallic Pt substrate on the FTO, although the Pt surface may also have contributed to the overall catalytic performance.

The PEDOT/nano-Ni/rGO on Pt/FTO was catalytically extraordinarily robust. It yielded a consistent 1.10-1.15 mA/ $\mathrm{cm}^{2}$ for over $40 \mathrm{~h}$ of constant light illumination (Figure 5). When the light was then turned off, the current fell to its earlier measured dark current. After the light was again turned on, the photocurrent recovered completely, at which level it continued up to the $50 \mathrm{~h}$ mark.

\subsection{Studies on the gas bubbles produced by the PEDOT/nano-Ni/rGO on Pt/FTO.}

During the above work, gas bubbles could be seen to form and release on the 
PEDOT/nano-Ni/rGO film containing $125 \mathrm{mg}$ nano-Ni and $6 \mathrm{mg}$ rGO. To determine the identity of the gas being generated, we collected and tested it using a specialized, sealed cell (Figure S1). The cell comprised of two sealed half-cells interfaced to each other via a proton conducting Nafion 117 membrane. The OER half-cell was constantly flushed with a steady stream of argon as a carrier gas; the gas outlet was connected to a dedicated gas chromatograph (as described in the Experimental Section). Periodic GC measurements indicated that the argon carrier gas passing through the OER half-cell was pure before turning the cell on but contained a large peak whose retention time corresponded to that of oxygen $\left(\mathrm{O}_{2}\right)$ while the cell was on (Figure S2). A small peak due to hydrogen $\left(\mathrm{H}_{2}\right)$, which presumably crossed-over the Nafion membrane from the other half-cell, was also observed. Tiny peaks corresponding to nitrogen $\left(\mathrm{N}_{2}\right)$ were also occasionally detected as a shoulder on the oxygen peak; these were due to small air leaks into the system.

The gas ratios were determined by integrating the peaks and found to be typically 96 $\mathrm{O}_{2}: 4 \mathrm{H}_{2}$ without light illumination. With light illumination, representative gas ratios were $89 \mathrm{O}_{2}: 9 \mathrm{H}_{2}: 2 \mathrm{~N}_{2}$. Neglecting $\mathrm{H}_{2}$, which came from the other half-cell, and trace $\mathrm{N}_{2}$, which came from the air, $\mathrm{O}_{2}$ was the only gas detected, both with and without light illumination. Gas bubbles formed on the Pt mesh counter electrode were also (and separately) shown to be pure $\mathrm{H}_{2}$ using the same equipment.

2.6 Changes in the electrolyte. As noted in section 2.1, PEDOT is susceptible to over-oxidation at pHs above 12 when biases of $>0.8 \mathrm{~V}$ are applied. For this reason, the experiments were performed at $\mathrm{pH}$ 12. The electrolyte was not buffered since watersplitting effectively generates net protons at the anode, meaning that the $\mathrm{pH}$ should slowly 


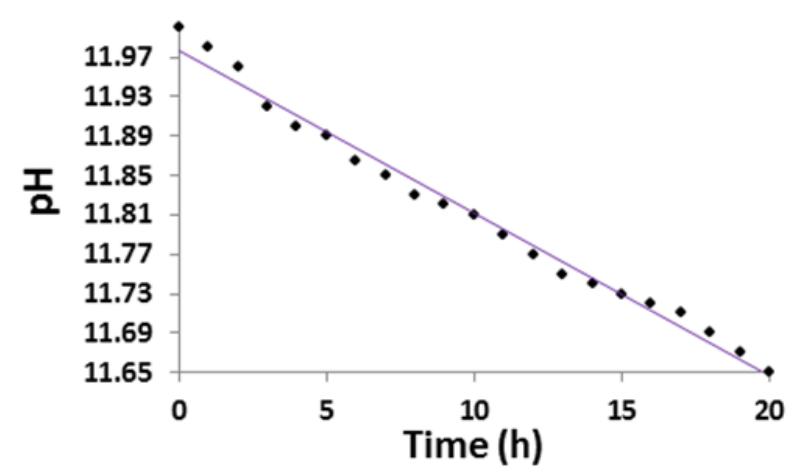

Figure 6. $\mathrm{pH}$ change during the first $20 \mathrm{~h}$ of the experiment displayed in Figure 5.

decrease in the electrolyte about the coating. This expected change in $\mathrm{pH}$ provides a convenient means of testing for water oxidation at the coating. Figure 6 shows that the $\mathrm{pH}$ in the $\mathrm{O}_{2}$-generating anode half-cell decreased by $0.35 \mathrm{pH}$ units during the first $20 \mathrm{~h}$ of operation. This is consistent with and indicative of water oxidation.

To check whether the electrode had formed any peroxide, which is an alternative oxidation product, we tested the solution after 5 h of operation with Qantofix ${ }^{\circledR}$ peroxide test strips that were capable of detecting $\geq 180 \mu \mathrm{g}$ of peroxide in the volume of electrolyte present. None was detected. As a total charge of $86.2 \mathrm{C}$ had flowed through the cell during that time and peroxide generation involves $2 \mathrm{~mol} \mathrm{e}^{-}$per mol peroxide formed, $\leq 0.000012 \%$ of the charge was indicated to have been involved in peroxide formation.

2.7 Studies on Other Possible Oxidation Processes. In order to further assess the incidence of other oxidation processes (outside of water oxidation), we examined the current profile, without light illumination, during the first few minutes of catalytic testing of the control films comprising $125 \mathrm{mg}$ nano-Ni and $6.0 \mathrm{mg}$ rGO only (without any PEDOT) (Figure 7(a)) and PEDOT containing 6.0 mg rGO (Figure 7(b)). The control film comprising only $6 \mathrm{mg}$ of rGO displayed a stable, unchanging current (Figure 7(c)). 


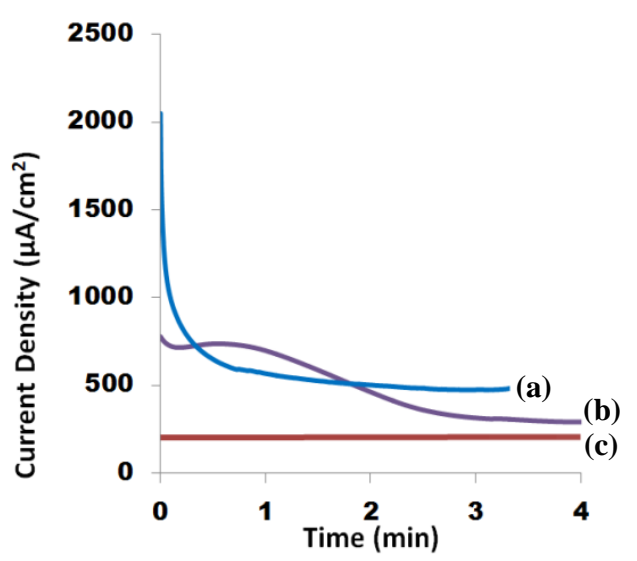

Figure 7. Chronoamperograms over the first 4 min of operation, at $0.80 \mathrm{~V}$ (vs $\mathrm{Ag} / \mathrm{AgCl}$ ) in $0.2 \mathrm{M} \mathrm{Na}_{2} \mathrm{SO}_{4}(\mathrm{pH} \mathrm{12})$ without light illumination, of FTO glass slides coated with control thin films comprising of: (a) $125 \mathrm{mg}$ nano-Ni and $6.0 \mathrm{mg}$ rGO only (without any PEDOT), (b) PEDOT containing 6.0 mg rGO, and (c) 6.0 mg rGO.

As can be seen in Figure 7(a), the nano-Ni/rGO control film without any PEDOT exhibited a current spike of up to $\sim 2,100 \mu \mathrm{A} / \mathrm{cm}^{2}$ in the first few seconds. This stands in contrast to the flat current profile of the rGO control film in Figure 7(c) and is consistent with the expected oxidation of the Ni catalyst surface. The oxidation was fully complete after 3 min (charge consumed: 0.293 C), with an unchanging, stable current thereafter. A control comprising PEDOT and $125 \mathrm{mg}$ of nano-Ni displayed a comparable profile.

Figure 7(b) similarly shows a transient oxidation of the PEDOT/rGO control film that is indicative of further oxidation of the PEDOT, as seen previously. ${ }^{2,3}$ That oxidation was complete after 4 min (charge consumed: $0.607 \mathrm{C}$ ), with a stable current thereafter. PEDOT is well-known to disintegrate/delaminate upon over-oxidation due to physical stresses arising from oxidatively-induced morphological changes in the coating and breaks in the polymer chains. ${ }^{33}$ The robust integrity of the coating over $50 \mathrm{~h}$ of continuous operation (Figure 5) indicates that the polymer was not further oxidized. 
The flat, unchanging current of the control film containing only $6.0 \mathrm{mg}$ rGO (Figure 7(c)) was not surprising. As noted earlier, the GO used in the film was prepared with a large excess of the powerful oxidant $\mathrm{KMnO}_{4}$, in sulfuric acid. As such, it was not subject to additional oxidation. This was further confirmed by the absence in the above GC studies of products that would result from such an oxidation, namely, $\mathrm{CO}$ or $\mathrm{CO}_{2}$ gas (Figure S2). The only oxidation process that could have been expected in this respect was a reversal of the partial reduction to rGO that was performed immediately prior to catalytic testing. The flat current profile suggested, however, that such a reversal either did not occur or occurred only very slowly.

The stable currents after 4 min in Figures 7(a)-(c) were well below that sustained by the most active PEDOT/nano-Ni/rGO thin film over $50 \mathrm{~h}$ under the same conditions, which consumed 861.8 C. This charge is sufficient to 1-electron oxidize every monomer in the PEDOT and every $\mathrm{C}$ in the GO >4-times over. The PEDOT coating would have delaminated long before every monomer was oxidized. Moreover, as noted earlier, small changes in the ratio of the components present in this most active film led to notable declines in current. These features are inconsistent with and could not have arisen if the observed currents were due to one of the components in that film being oxidatively consumed in any substantial proportion.

The minimum quantity of oxygen produced by the most active PEDOT/nano$\mathrm{Ni} / \mathrm{rGO}$ film could be determined by integration of the oxygen peak in the above GC studies (Figure S2) and comparison with a previously determined calibration curve. This indicated that at least 50.9\% (dark) and 52.2\% (under light illumination) of the volume of oxygen expected from the electrons passing through the electrode was injected through 
the GC column in these studies. These results were, however, an under-estimate because the cell used in those studies (Figure S1) could not be made gas-tight and had to be operated with a positive pressure of carrier gas to exclude air ingress. This resulted in leaking of an unquantifiable proportion of the product gas.

It can be concluded that the only possible oxidation process that could have occurred in the system beyond water oxidation, was the reversal of the partial reduction of GO performed immediately before catalytic testing. That represented $<0.1 \%$ of the overall charge that passed through the electrode during $50 \mathrm{~h}$ of operation (Figure 5). Accordingly, the Faradaic efficiency for oxygen generation was likely toward $>99.9 \%$, but unequivocally more than $50.9 \%$ (dark) or $52.9 \%$ (light). Even if the latter percentages were the more accurate, they indicate a 4-fold faster generation of $\mathrm{O}_{2}$ than the bare $\mathrm{Pt}$ electrode under the same conditions.

2.8 Characterization of the PEDOT/Nano-Ni/rGO Electrode. To determine the molar composition of the most catalytically active PEDOT film, with $125 \mathrm{mg}$ nano-Ni and $6 \mathrm{mg}$ rGO, elemental analysis studies were undertaken. As the quantity of material in such a film was far below the minimum needed for an elemental analysis, multiple identical films were prepared on FTO glass, dried, carefully scraped off, and combined.

Analysis of the combined films indicated that they contained $21.00 \% \mathrm{Ni}, 8.54 \% \mathrm{~S}$, 60.10\% C, and no Fe. As only PEDOT contains S, while rGO contains only C and nano$\mathrm{Ni}$ contains only $\mathrm{Ni}$, it was possible to calculate the molar ratio of PEDOT : $\mathrm{Ni}$ : rGO to be 4.5 (C; PEDOT) : 1 (Ni) : 9.5 (C; other).

The morphology of the PEDOT/Nano-Ni/rGO film was examined using Scanning 


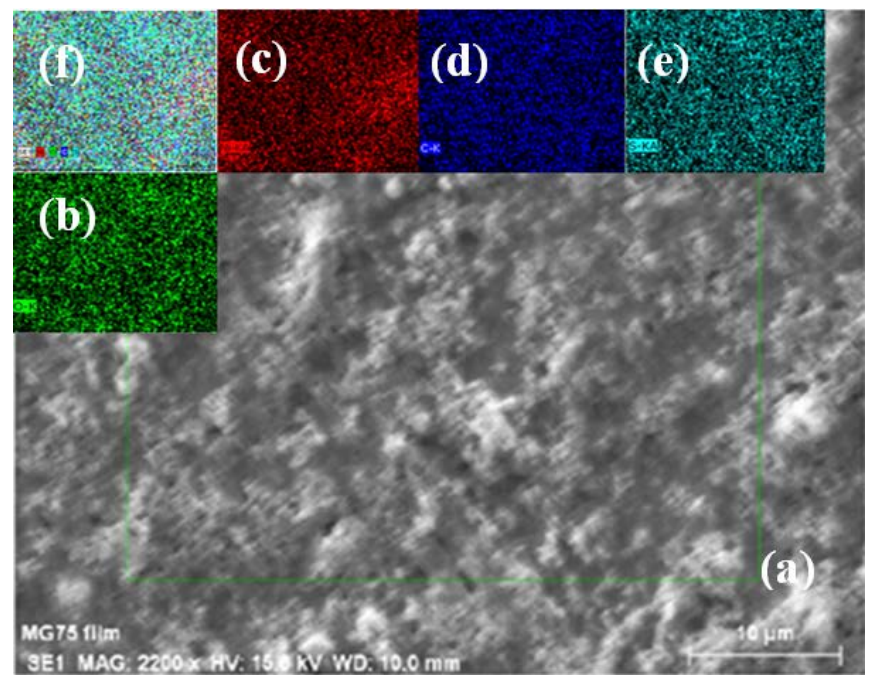

Figure 8. (a) Scanning electron microscope (SEM) image of PEDOT/Nano-Ni/rGO containing $125 \mathrm{mg}$ nano-Ni and $6 \mathrm{mg}$ rGO. The inset images show the elemental distributions, using EDX, of: (b) O, (c) Ni, (d) C, (e) S, and (f) O, Ni, C, S together.

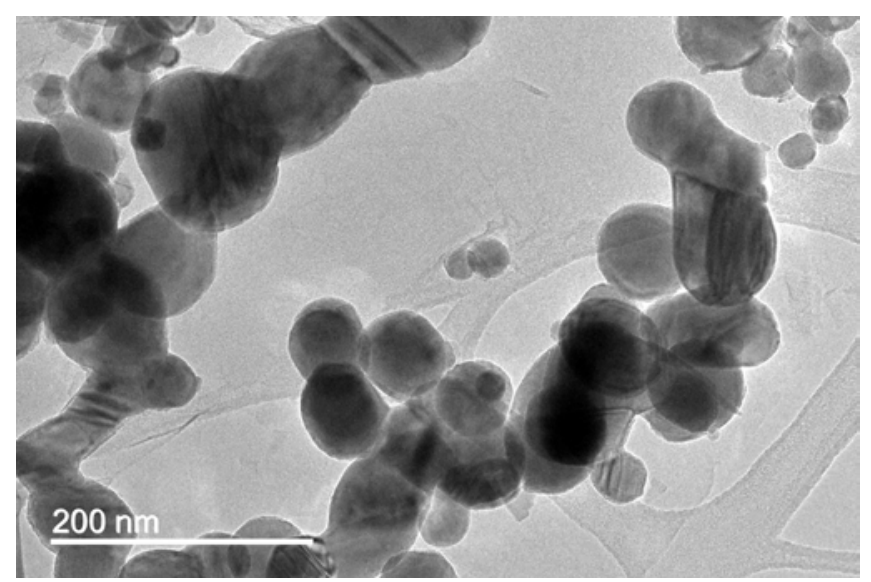

(a)

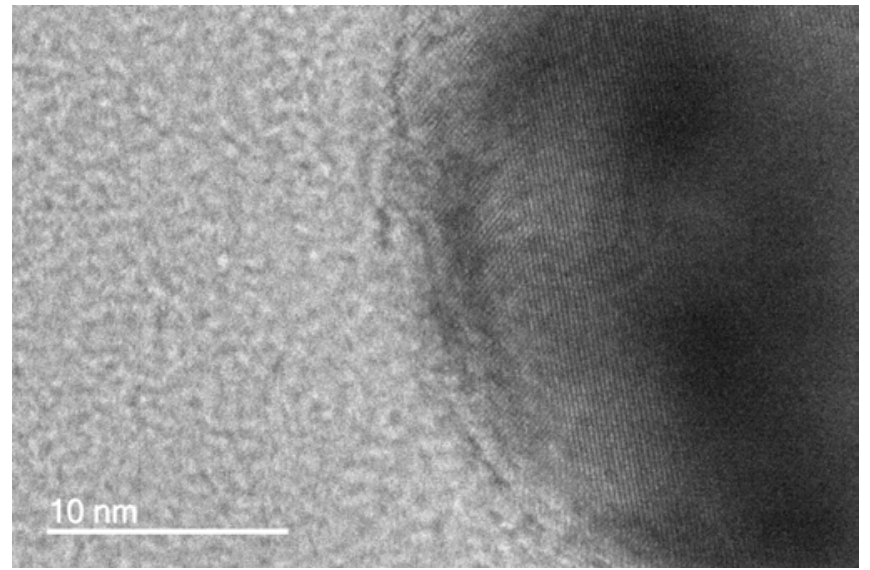

(b)

Figure 9. (a) Transmission electron microscopy (TEM) image of PEDOT/Nano-Ni/rGO, showing the rGO plates and the nano-Ni particles. (b) TEM of the nano-Ni/PEDOT interface. 

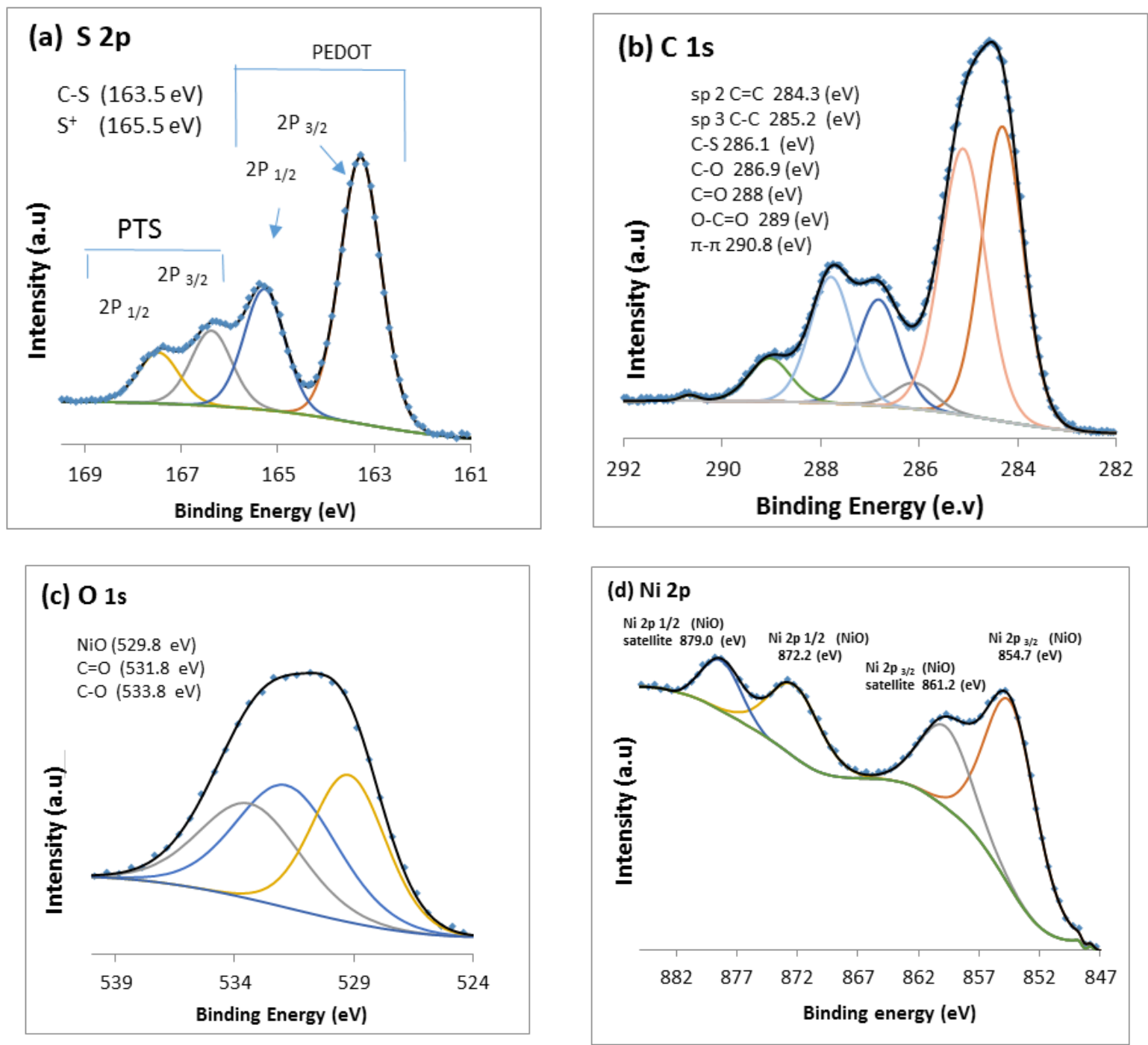

Figure 10. XPS spectra using a monochromatic $\operatorname{MgK} \alpha$ X-ray source of PEDOT/nano$\mathrm{Ni} / \mathrm{rGO}$ after $6 \mathrm{~h}$ at $0.8 \mathrm{~V}$ (vs. $\mathrm{Ag} / \mathrm{AgCl})$ in $0.2 \mathrm{M} \mathrm{Na}_{2} \mathrm{SO}_{4}(\mathrm{pH} 12)$ showing measured data (individual data points) and modelled data (solid lines) for the: (a) S 2p, (b) C 1s, (c) O 1s, (d) Ni 2p spectra.

Electron Microscopy (SEM). Samples for the SEM experiments were prepared by coating a PEDOT/Nano-Ni/rGO film on FTO glass with a $7 \mathrm{~nm}$ layer of $\mathrm{Pt}$ in order to provide a sufficient signal. Figure 8 depicts a representative SEM image of the deposited film, 
showing that it comprised a highly porous surface structure. EDX-mapping (Figure 8(b)(e)) indicated uniform distributions of Ni (nano-Ni), C (PEDOT and rGO), O (PEDOT and rGO), and S (PEDOT) over the film.

Transmission electron microscopy (TEM) (Figure 9(a)) showed that the nano-Ni particles and the rGO platelets were generally not in contact with each other, each being separately enveloped by the PEDOT. The nano-Ni particles were $20-50 \mathrm{~nm}$ in diameter (the dark structures in Figure 9(a)), while the rGO plates were 200-300 nm wide and long (shown as the light-coloured background structures in Figure 9(a)). Figure 9(b) shows a TEM of the interface between the PEDOT and the nano-Ni. As can be seen, the PEDOT generally made seamless contact with the Ni lattice. This was also true for the rGO.

To establish whether the water oxidation catalysis changed the elemental composition and chemical states of the above PEDOT/nano-Ni/rGO film, it was further analysed, after $6 \mathrm{~h}$ of continuous operation, with X-ray photoelectron spectroscopy (XPS). The resulting spectra, which are shown as the individual data points in Figure 10 closely matched modelled data for PEDOT/nano-Ni/rGO, indicating that there had been no substantive elemental or chemical changes to the film.

The survey spectrum indicated peaks corresponding to O 1s, C 1s, Ni 2p and S 2p. The $\mathrm{O}$ 1s and $\mathrm{C}$ 1s spectra were characteristic of PEDOT and rGO, while the $\mathrm{S}$ 2s spectra derived from PEDOT. The C 1s spectrum contained deconvolution peaks at 284.3, 285.2, 286.1, 286.9, 288.0 and $290.8 \mathrm{eV}$ (Figure 10(b)). The peak at $284.3 \mathrm{eV}$ represented a sp ${ }^{2}$ carbon hybrid, characteristic of $\mathrm{C}=\mathrm{C}$ bonds. The peak at $285.2 \mathrm{eV}$ represented a $\mathrm{sp}^{3}$ carbon hybrid arising from C-C and C-H bonds. The peak at $286.1 \mathrm{eV}$ refers to the C-S bond. Finally, the peaks at $288.0 \mathrm{eV}$ and $289.0 \mathrm{eV}$ refer to $\mathrm{C}=\mathrm{O}$ and $\mathrm{O}-\mathrm{C}=\mathrm{O} \boldsymbol{\pi}-\boldsymbol{\pi}$ 
interactions respectively. ${ }^{34-42}$ The S 2p spectrum displayed peaks at $163.5 \mathrm{eV}$ and 165.5 $\mathrm{eV}$ that corresponded to the $\mathrm{S} 2 \mathrm{p}_{3 / 2}$ and $2 \mathrm{p}_{1 / 2}$ binding energies. These derived from the C$\mathrm{S}$ bond and $\mathrm{S}^{+}$, arising from the $\mathrm{S}$ atoms of the PEDOT fragments. The other two small peaks refer to $2 \mathrm{p}_{3 / 2}$ and $2 \mathrm{p}_{1 / 2}$ arising from sulfonic groups in the PTS structure. ${ }^{43-47}$ The $\mathrm{O}$ 1s spectrum of the film had peaks at $529.8 \mathrm{eV}, 531.8 \mathrm{eV}$ and $533.8 \mathrm{eV}$. They relate to the binding energy of the Ni-O, $\mathrm{C}=\mathrm{O}$ and $\mathrm{C}-\mathrm{O}$ bonds respectively. ${ }^{48-50}$ Finally, for the $\mathrm{Ni}$ spectrum, there were two main peaks due to $\mathrm{Ni} 2 \mathrm{p}_{1 / 2}$ and $2 \mathrm{p}_{3 / 2}$ transitions in the range 848-885 eV (Figure 10(d)). The main peak at $854.7 \mathrm{eV}$ had an intense satellite at 861.2 $\mathrm{eV}$, which represents $\mathrm{Ni} 2 \mathrm{p}_{1 / 2}$, while the peak at $872.2 \mathrm{eV}$ with an intense satellite at 879.0 $\mathrm{eV}$ was due to the presence of $\mathrm{Ni} 2 \mathrm{p} 3 / 2$, both of which are characteristic of the $\mathrm{Ni}^{2+}$ ion. ${ }^{51,52}$

A number of conclusions could be drawn from the above characterization studies. Firstly, the observed amplification of the catalytic effect did not derive from an interaction between the nano-Ni and the rGO in the film. These components were generally separately enveloped by the PEDOT, which formed an apparently seamless interface with them. The amplification also did not arise from chemical or elemental changes in the film during catalysis. Nor was it due to a catalytic effect arising from residual Fe left over from the polymerisation step. Indeed, we could not detect any significant differences in the SEM, TEM, and other characterization data for the higher and lower performing PEDOT/nano-Ni/rGO coatings. The apparent similarity in structure indicated that the relative catalytic properties of these films were most likely determined by an interplay between the activity of the $\mathrm{Ni}$, the active surface area present and the average conductivity at the given film composition. 

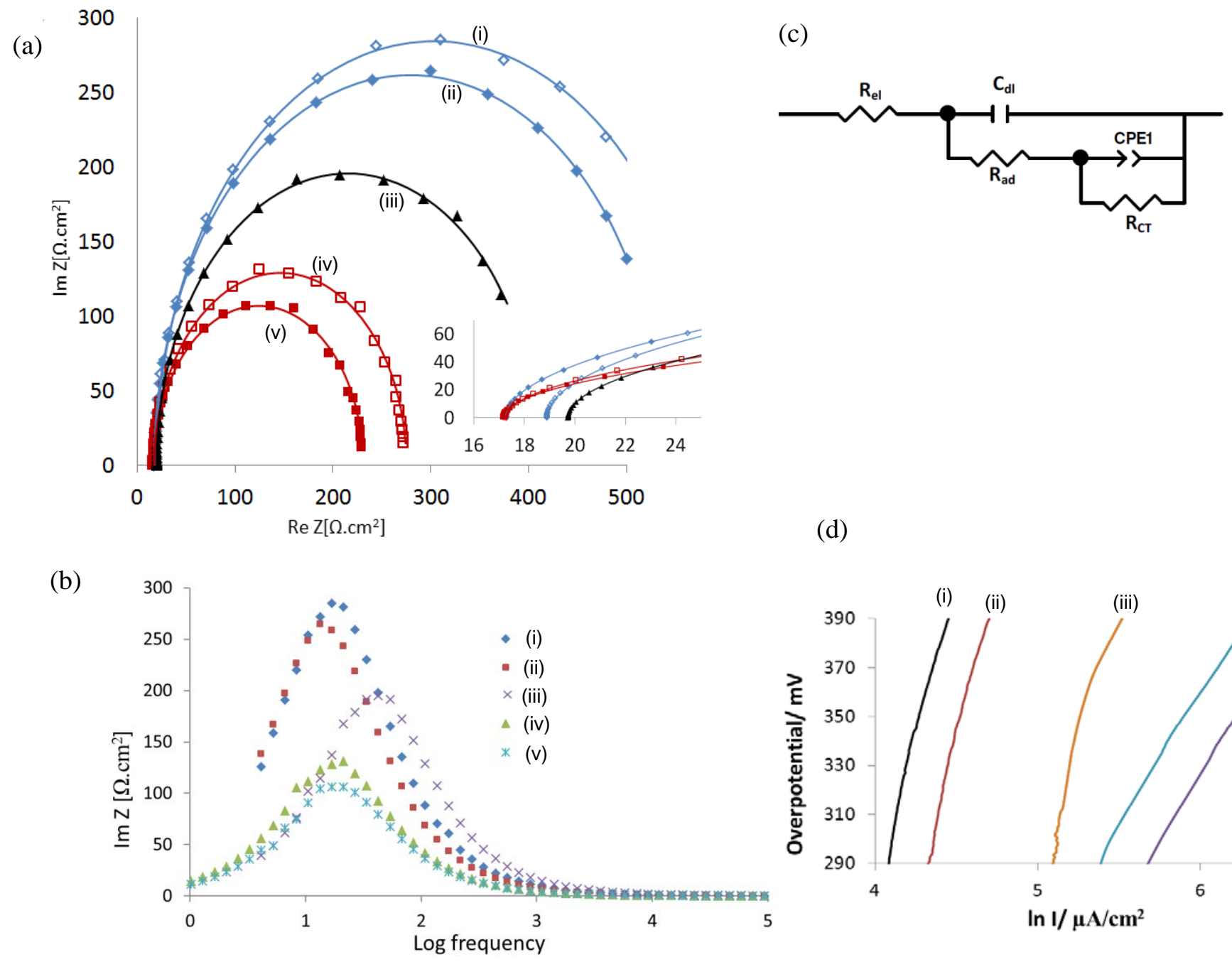

(d)

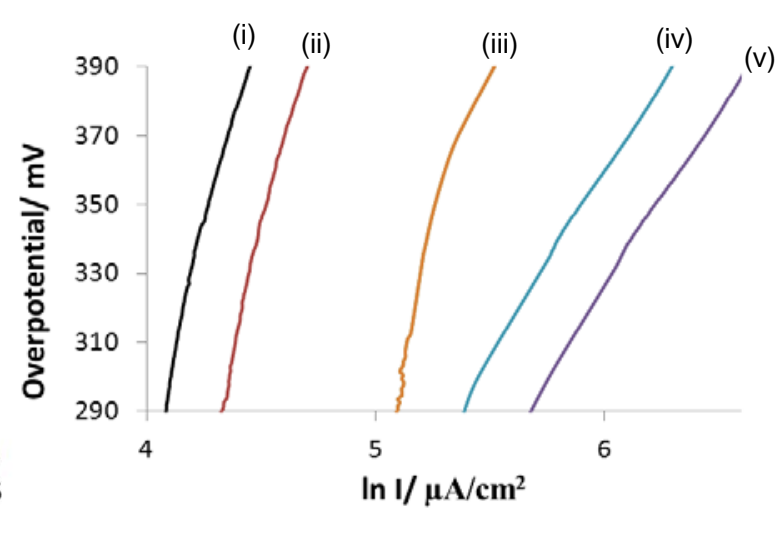

Figure 11. (a) Nyquist and (b) Bode plots at $0.8 \mathrm{~V}$ vs $\mathrm{Ag} / \mathrm{AgCl}$ (pH 12), showing measured data (individual data points) and modelled data (solid lines) using the equivalent circuit depicted in (c), as well as (d) Tafel plots of: (i) PEDOT only (dark; no light illumination), (ii) PEDOT only (with light illumination), (iii) Pt only, (iv) Pt overcoated with PEDOT/nano-Ni/rGO containing $125 \mathrm{mg}$ nano-Ni and $6.0 \mathrm{mg}$ rGO (dark; no light illumination), and (v) Pt overcoated with PEDOT/nano-Ni/rGO containing $125 \mathrm{mg}$ nano-Ni and $6.0 \mathrm{mg}$ rGO (with light illumination). 
Table 1. Data from modelling of electrochemical impedance spectroscopy (ohmic resistance $\left(\mathrm{R}_{\mathrm{el}}\right)$, adsorption resistance $\left(\mathrm{R}_{\mathrm{ad}}\right)$, diffuse layer capacitance $\left(\mathrm{C}_{\mathrm{dl}}\right)$, catalytic charge transfer resistance $\left(\mathrm{R}_{\mathrm{CT}}\right)$, and capacitance expressed in terms of a constant phase element $\left(\mathrm{Q}_{\mathrm{CPE}}, \mathrm{n}_{\mathrm{CPE}}\right.$, and $\left.\mathrm{C}_{\mathrm{CPE}}\right)$ ). ${ }^{53}$ Data from Tafel plot studies (slope (A), exchange current density $\left.\left(i_{o}\right)\right)$. ('dark' $=$ without light illumination; 'light' $=$ with light

\begin{tabular}{|l|c|c|c|c|c|c|c|c|c|}
\hline Sample & $\begin{array}{c}\mathrm{R}_{\mathrm{el}} \\
\Omega \mathrm{cm}^{2}\end{array}$ & $\begin{array}{c}\mathrm{R}_{\mathrm{ad}} \\
\Omega \mathrm{cm}^{2}\end{array}$ & $\begin{array}{c}\mathrm{C}_{\mathrm{dl}} \\
\mu \mathrm{F} \mathrm{cm}\end{array}$ & $\begin{array}{c}\mathrm{R}_{\mathrm{CT}} \\
\Omega \mathrm{cm}^{2}\end{array}$ & $\begin{array}{c}\mathrm{Q}_{\mathrm{CPE}} \\
\mu \Omega^{-1} \mathrm{~cm}^{-} \\
{ }^{\mathrm{n}} \mathrm{s}^{\mathrm{n}}\end{array}$ & $\mathrm{n}_{\mathrm{CPE}}$ & $\begin{array}{c}\mathrm{C}_{\mathrm{CPE}} \\
\mu \mathrm{F} \mathrm{cm}{ }^{-2}\end{array}$ & $\begin{array}{c}\mathrm{A} \\
\mathrm{mV} / \mathrm{dec}\end{array}$ & $\begin{array}{c}i_{\mathrm{o}} \\
\mu \mathrm{A} \\
\mathrm{cm}^{2}\end{array}$ \\
\hline PEDOT (dark) & 18.9 & 420.3 & 16.1 & 148.3 & 0.07 & 0.88 & 0.01 & 277 & 20.6 \\
\hline PEDOT (light) & 17.3 & 400.1 & 20.9 & 122.9 & 0.14 & 0.88 & 0.02 & 272 & 25.9 \\
\hline Pt only & 19.7 & 270.4 & 9.9 & 120.7 & 0.06 & 0.92 & 0.02 & 250 & 50.5 \\
\hline $\begin{array}{l}\text { PEDOT/nano- } \\
\text { Ni/rGO on Pt/FTO } \\
\text { (dark) }\end{array}$ & 17.3 & 132.4 & 34.0 & 125.3 & 0.25 & 0.89 & 0.05 & 110 & 15.2 \\
\hline $\begin{array}{l}\text { PEDOT/nano- } \\
\text { Ni/rGO on Pt/FTO } \\
\text { (light) }\end{array}$ & 17.2 & 110.4 & 38.9 & 103.2 & 0.40 & 0.88 & 0.08 & 104 & 18.0 \\
\hline
\end{tabular}

illumination).

2.9 EIS and Tafel Plot Studies. To further investigate the origin of the catalytic amplification, electrochemical impedance spectroscopy (EIS) and Tafel plot studies were undertaken. Figure 11(a)-(b) depict the Nyqist and Bode plots respectively, at $0.8 \mathrm{~V}$ vs $\mathrm{Ag} / \mathrm{AgCl}$ and $\mathrm{pH}$ 12, of: (i)-(ii) the control PEDOT (only) electrode, with and without illumination, (iii) the control bare Pt electrode, and (iv)-(v) the Pt electrode overcoated with the most active PEDOT/nano-Ni/rGO, with and without illumination. For each sample, two distinct processes can be distinguished in the Nyquist plot: (I) a large arc at 
intermediate to low frequencies $(10-100 \mathrm{~Hz})$, which is clearly visible in the main graph in Figure 11(a), and (II) a small arc at high frequencies $(1,000-10,000 \mathrm{~Hz})$ that is barely discernible at low $\mathrm{Z}$ values in the inset graph in Figure 11(a). The latter is characteristic of charge transfer during catalysis. The frequencies of the former are typical of interfacial and solution processes. Previous studies at $\mathrm{pH} 12$ have assigned such low to intermediate frequency arcs to adsorption processes involving transfer of ions (charge carriers) from the diffuse layer to the catalyst. ${ }^{54}$ Accordingly, we modelled the EIS data with the equivalent circuit shown in Figure 11(c). ${ }^{55}$ The modelled results are depicted as the solid lines in Figure 11(a). As can be seen, an excellent match was achieved with the measured data (shown by the individual data points in Figure 11(a)). Table 1 lists key results of the modelling.

The capacitance $\mathrm{C}_{\mathrm{dl}}$ provides a comparative measure of the electrochemically active area of the samples tested. As can be seen in Table 1, the control bare Pt exhibited a substantially lower capacitance $\left(9.9 \mu \mathrm{F} \mathrm{cm}^{-2}\right)$ than the Pt/PEDOT/nano-Ni/rGO (34.0 $\mu \mathrm{F}$ $\mathrm{cm}^{-2}$ without light illumination, $38.9 \mu \mathrm{F} \mathrm{cm}^{-2}$ with light illumination). The $\mathrm{Pt} / \mathrm{PEDOT} / \mathrm{nano}-\mathrm{Ni} / \mathrm{rGO}$ clearly had an electroactive area that was substantially larger than the bare Pt. The catalytic performance of the Pt/PEDOT/nano-Ni/rGO electrode was therefore due, in part, to a large catalytically active area.

The resistance associated with adsorption, $\mathrm{R}_{\mathrm{ad}}$, and the charge transfer resistance, $\mathrm{R}_{\mathrm{CT}}$, of the PEDOT/nano-Ni/rGO on Pt/FTO $\left(\mathrm{R}_{\mathrm{ad}} 110.4 \Omega \mathrm{cm}^{2}\right.$ and $\mathrm{R}_{\mathrm{CT}} 103.2 \Omega \mathrm{cm}^{2}$ $\left(\mathrm{R}_{\text {total }}=213.6 \Omega \mathrm{cm}^{2}\right)$ with light illumination; $\mathrm{R}_{\mathrm{ad}} 132.4 \Omega \mathrm{cm}^{2}$ and $\mathrm{R}_{\mathrm{CT}} 125.3 \Omega \mathrm{cm}^{2}$ $\left(\mathrm{R}_{\text {total }}=257.7 \Omega \mathrm{cm}^{2}\right)$ without light illumination) were also lower than the bare $\mathrm{Pt}\left(\mathrm{R}_{\mathrm{ad}}\right.$ $270.4 \Omega \mathrm{cm}^{2}$ and $\mathrm{R}_{\mathrm{CT}} 120.7 \Omega \mathrm{cm}^{2}\left(\mathrm{R}_{\text {total }}=391.1 \Omega \mathrm{cm}^{2}\right)$ ). The PEDOT/nano-Ni/rGO 
was therefore a more active catalyst than the bare Pt, per unit area, at least under the testing conditions.

Accordingly, the PEDOT/nano-Ni/rGO on Pt/FTO achieved its high catalytic performance because it had a larger electroactive area that was also more active per unit area. By contrast, the PEDOT alone displayed a smaller area that was less active.

The ohmic resistance, $\mathrm{R}_{\mathrm{el}}$, was of the same order for all samples (17.2-19.7 $\Omega$ $\mathrm{cm}^{2}$ ), as would be expected (Table 1).

Figure 11(d) shows Tafel plots of the catalysts, with results listed in the last two columns of Table 1 . The exchange current density, $i_{o}$, provides a measure of the rate of catalysis at the reversible potential, when the overpotential is zero. As can be seen, the bare Pt displayed the highest $i_{o}$, indicating that it had the highest intrinsic catalytic capability at zero overpotential. Interestingly, the PEDOT control exhibited higher $i_{o}$ values with and without light illumination than the PEDOT/nano-Ni/rGO. This indicates that PEDOT is itself an OER catalysis. However, the high Tafel slopes, A, of the PEDOT control indicates that such a catalytic contribution would have been small under the test conditions in Figure 5.

By contrast, catalysis by the PEDOT/nano-Ni/rGO was very strongly activated by the application of the voltage bias. The extent of that activation is confirmed by the Tafel slope. As can be seen, the PEDOT/nano-Ni/rGO on Pt/FTO required only $104 \mathrm{mV}$ (with light illumination) and $110 \mathrm{mV}$ (without light illumination) to increase the reaction rate by a factor of 10 at $\mathrm{pH} 12$. This was very much less than the bare Pt $(250 \mathrm{mV})$ and the control PEDOT (272-277 mV), explaining why the PEDOT/nano-Ni/rGO on Pt/FTO was so much more active at $0.8 \mathrm{~V}$ vs $\mathrm{Ag} / \mathrm{AgCl}$. It also supersedes the Tafel slope of other, 
highly active Pt-based catalysts, such as Pt on carbon (Pt/C), which was reported to be $120 \mathrm{mV} / \mathrm{dec}$ under adsorption controlled conditions. ${ }^{56}$

2.10 The Origin of the Catalytic Amplification. It therefore appears that the catalytic amplification derived from a confluence of two effects: (i) a large catalytically active area that became (ii) highly active per unit area when a voltage bias was applied to it. The extreme sensitivity of the catalytic amplification to the precise composition of the PEDOT/nano-Ni/rGO film (as demonstrated in Figures 2 and 3) further indicates that these two effects were intimately connected with the precise composition of the film. That is, the catalytic amplification also appears to be associated with the very particular ratio of catalyst density to conductivity and thickness in the film.

During OER catalysis in basic media, electrons are generated at a catalyst. At a bias of $0.8 \mathrm{~V}$, PEDOT is in its conducting form. When interfaced with an OER catalyst like nano-Ni, that is generating electrons, a PEDOT support will transport those electrons to the external circuit of the cell. In so doing, it would, effectively, also transmit the applied bias to the catalyst. The PEDOT in the above PEDOT/nano-Ni/rGO film containing $125 \mathrm{mg}$ nano-Ni and $6.0 \mathrm{mg}$ rGO, was clearly unusually efficient at carrying out these tasks. That could only have been the case if the electrical pathways between the catalyst sites and the external circuit were short and low-resistance.

The earlier-described characterization studies showed that the PEDOT in the film was porous. The PEDOT also enveloped and seamlessly interfaced with the additives in the film. In so doing, it would certainly have electrically connected a large number of catalytically capable $\mathrm{Ni}$ atoms to the external circuit. If the electrical pathways were, 
additionally, short and low-resistance then that would explain the high catalytically active area. It would also explain the strong transmission of the applied bias to the catalytic sites.

In other words, it appears that the composition of the above film, relative to the other, less catalytically active films described above, was such as to uniquely connect the largest number of catalytic sites by the shortest, least-resistive pathway. That pathway may have included rGO platelets.

That is, the amplification appears to have derived from a synergistic matching of the electrical connectivity, conductivity and catalytic capacity of the film.

The net result was the creation of a catalytic effect having an order of magnitude higher activity than bare Pt under the conditions of testing. To the best of our knowledge, the above amplification is the largest yet noted for PEDOT as a proportion of the comparable Pt catalytic activity under the same conditions. ${ }^{1}$

The general nature of the above conclusions suggest that the above approach may potentially provide a means to maximize the utility of other thin-film conducting polymers in other catalytic processes.

\section{CONCLUSIONS}

In this work we have studied the conditions under which thin-film conducting polymer supports may be induced to synergistically amplify catalysis. Composite PEDOT films containing nano-Ni and rGO have been studied as (photo)electrocatalysts of water oxidation in $0.2 \mathrm{M} \mathrm{Na}_{2} \mathrm{SO}_{4}$ with the $\mathrm{pH}$ adjusted to 12. Films containing PEDOT : nano$\mathrm{Ni}$ : rGO in the specific molar ratio of 4.5 (C; PEDOT) : 1 (Ni) : 9.5 (C; other) proved to be particularly active, especially when overcoated on a Pt electrode. Control films 
containing other combinations of the above components, produced notably lower currents. The above PEDOT/nano-Ni/rGO on Pt/FTO film generated a sustained current density of $1.10-1.15 \mathrm{~mA} / \mathrm{cm}^{2}$ at $0.80 \mathrm{~V}$ (vs Ag/AgCl) over $>40 \mathrm{~h}$ of operation under constant light illumination of 0.25 sun. This was an order of magnitude greater than an equivalent bare Pt electrode, which produced $<0.15 \mathrm{~mA} / \mathrm{cm}^{2}$ under the same conditions. Oxygen was the sole product detected, with an estimated Faradaic efficiency of $>99.9 \%$. SEM/EDX, TEM, XPS, EIS and Tafel plot studies showed that the catalytic amplification was created by the PEDOT in the above film. The amplification derived from a high catalytically active area coupled with a high activity per unit area under the applied voltage bias. This suggested that, in the above film, an optimum ratio of catalyst density to conductivity and thickness led to the PEDOT electrically connecting the largest number of catalytic sites (thereby maximizing the catalytically active area) by the shortest, least-resistive pathway (thereby minimizing the Tafel slope). That is, the amplification was likely created by a synergistic matching of the connectivity, conductivity, and catalytic capacity of the film. Thin-film coatings of this type have several potential applications. For example, they may potentially provide a useful interfacial layer between a photo-activated semiconductor and the liquid water electrolyte in water-splitting photoelectrochemical cells. Such an interfacial layer could catalyse water-splitting at a more accelerated rate, whilst simultaneously suppressing photocorrosion of the semiconductor.

\section{EXPERIMENTAL}


4.1 Materials and Methods. The following materials were used (Supplier): Fluorine-doped tin oxide (FTO) slides (Zhuhai Kaivo Electronic Components Co.); glass microscope slides (Australia Optics); iron(III) p-toluenesulfonate (Fe(III)-pTS) (Sigma Aldrich Co.); 3,4ethylenedioxythiophene (EDOT) (Sigma Aldrich Co.); graphite flakes (3772) (Asbury Graphite Mills USA), Ni nanoparticles (20 nm; Skyspring Nanomaterials). FTO and glass substrates were cleaned using a PLAMAFLO PDC-FMG Plasma cleaner and a DIG UV PSD PR SERIES digital UV Ozone cleaner. Sonication was carried out using a B2500R-MTH sonicator. Spin-coating onto the substrates was carried out using a WS-400B-6NPP/LITE spin-coater. Centrifugationwashing steps were carried out using using a ProSciTech TG16WS centrifuge.

Thickness measurements were made using a Vccco Dektak 150 profilometer. The electrical resistivity of the films after deposition, were measured using an HG29315 Jandel equipped with a four-point probe. The resistivity (in $\Omega /$ square) was calculated using the formula $\rho=\mathrm{t}$ Rs, where $\rho$ is resistivity, $t$ is sheet thickness and $R_{\mathrm{s}}$ is sheet resistance. Resistivity can then be converted to conductivity (S/cm). Scanning Electron Microscopy (SEM) images were taken using a JEOL 7500 FESEM. Elemental analysis was done by the Campbell Microanalytical laboratory at the University of Otago, New Zealand. $\mathrm{pH}$ measurements were done with an Oakton $\mathrm{pH}$ /conductivity meter. XPS measurements were carried out using a XPS PHI660 instrument.

4.2 GO Synthesis. In order to prepare fully oxidized graphite, dry expandable graphite flakes were first thermally treated at $700{ }^{\circ} \mathrm{C}$ in a vertical tube furnace under $\mathrm{N}_{2}$ atmosphere. The resulting expanded graphite (EG) was used as a precursor for GO synthesis, following previously described methods. ${ }^{57-61}$ Briefly, $1 \mathrm{~g}$ of EG and $200 \mathrm{~mL}$ of $\mathrm{H}_{2} \mathrm{SO}_{4}$ were mixed and stirred in a 
flask for $24 \mathrm{~h} . \mathrm{KMnO}_{4}$ (5 g) was then added to the mixture slowly. The mixture was transferred into an ice bath and $200 \mathrm{~mL}$ of DI water containing $50 \mathrm{~mL}$ of $30 \% \mathrm{H}_{2} \mathrm{O}_{2}$ were poured slowly into the mixture. The suspension changed colour to light brown. After stirring for another 30 min, the resulting GO particles were washed and centrifuged with a $\mathrm{HCl}$ solution (9:1 water: c.HCl by volume), then centrifuged again and washed with DI water until the $\mathrm{pH}$ of the solution became 3 - 4. The resultant GO sheets were dispersed in deionized water by gentle shaking. Then, a GO dispersion in ethanol was prepared by extracting the water from the parent aqueous GO dispersion by repeated centrifugation-washing steps (6 times, for 10 - 30 min each, at 11000 rpm). ${ }^{62}$ The parent aqueous GO $(15 \mathrm{~mL})\left(\sim 2.5 \mathrm{mg} \mathrm{ml}^{-1}\right)$ was poured into a $50 \mathrm{ml}$ centrifuge tube (Nalgene), to which $20 \mathrm{ml}$ ethanol was added, followed by vigorous mixing using a vortex shaker. After each centrifuging, $30 \mathrm{ml}$ of the supernatant was poured off and replaced with $30 \mathrm{ml}$ of ethanol and then mixed vigorously by vortex shaking. This process was repeated a further 5 times to replace the water with ethanol. Finally, the dispersion was sonicated in a bath sonicator for $1 \mathrm{~h}$ before being centrifuged again to make a high concentration dispersion ( 30 mg/ml GO).

\subsection{Preparation of PEDOT, PEDOT/nano-Ni, PEDOT/nano-Ni/rGO on FTO-coated glass}

slides. Uncoated glass and FTO-coated glass slides were immersed in acetone within a thin-layer chromatography (TLC) chamber. The baths with the immersed slides were sonicated for 90 min, whereafter the slides were washed with water and dried by blowing air over them. The FTO and uncoated glass slides were then labelled. All slides were thereafter treated in a digital ozone-UV cleaner for 20 min to remove organic contaminants. The slides were then cleaned in a plasma cleaner in order to functionalize groups on the slide's surface with which to fix the coated 
chemical solutions during spin-coating. The FTO and glass substrates were heated to dryness on an IKA ${ }^{\circledR}$ RCT basic hotplate at $60^{\circ} \mathrm{C}$.

To prepare the PEDOT, PEDOT/nano-Ni, and PEDOT/nano-Ni/rGO films on FTO glass slides, the following procedure was used. Where applicable, GO ethanol solution (e.g. $0.2 \mathrm{ml}$ ) was transferred to a small glass vial and the volume increased to $1.2 \mathrm{ml}$ by adding absolute ethanol. The solution was sonicated for $10 \mathrm{~min}$ and then stirred with a magnetic stirrer for 7-8 min. Where applicable, Nano-Ni (e.g. $125 \mathrm{mg}$ ) was added gradually with magnetic stirring continuing for $2.5 \mathrm{~h}$ thereafter. A solution of dissolved Fe(III)-PTS (100 mg) in $0.15 \mathrm{ml}$ ethanol was then added to the mixture. The resulting solution $(100 \mu \mathrm{L})$ was dropcast onto the slide surface using a micropipette. The slides, which were uniformly $2 \mathrm{~cm}$ x $2 \mathrm{~cm}$ in size, were then spun at 2000 revolutions per min (rpm) for 180 s. After spin-coating, the sample was quickly transferred to a hotplate, where it was dried at $60{ }^{\circ} \mathrm{C}$ for $15 \mathrm{~min}$.

Vapour phase polymerisation was carried out in a separate conical flask (500 mL capacity), equipped with a rubber stopper containing a crocodile clip suspended above the bottom of the flask. EDOT (0.450 mL) was placed in the flask and the dried, spin-coated FTO or uncoated glass substrates were held above the EDOT solution by the crocodile clip, with the stopper in place. The stoppered conical flask was then placed in an oven at $60^{\circ} \mathrm{C}$ for $60 \mathrm{~min}$, during which time the EDOT vapour polymerised into PEDOT polymer on the slide surface. After polymerisation was complete, the sample was removed, washed very thoroughly with ethanol, and then left to dry overnight. The resulting thin-films covered an area of $4.2 \mathrm{~cm}^{2}$ on each slide.

The resulting dried FTO-coated samples were converted to usable electrodes by attaching a copper wire to the FTO surface with conductive silver paint and epoxy resin. When the silver 
paste was fully solidified, epoxy glue was used to cover the contact area of the wire as well as any exposed clean FTO glass surface.

Immediately prior to testing as a (photo)electrocatalyst, the GO present in all films was reduced electrochemically to rGO using cyclic voltammetry (performed in $0.2 \mathrm{M} \mathrm{Na}_{2} \mathrm{SO}_{4}$ (pH 12); 5 cycles between $-1.2 \mathrm{~V}$ and $0.8 \mathrm{~V}$, vs. Ag/AgCl, at $50 \mathrm{mV} / \mathrm{s}$ scan speed).

\subsection{Studies of PEDOT, PEDOT/Nano-Ni, and PEDOT/Nano-Ni/rGO on FTO as OER}

Photocatalysts. The resulting nanocomposite mixtures on the FTO-coated glass slides were employed as working electrodes within a fully-enclosed quartz cell $(5 \times 5 \times 5 \mathrm{~cm})$ placed inside a closed cabinet that comprised a Faraday cage. A Pt mesh $(1 \times 2 \mathrm{~cm})$ was used as the counter electrode. A BASi Ag/AgCl aqueous salt bridge (KCl, $3 \mathrm{M}$ ) served as reference electrode. The electrolyte employed was a $0.2 \mathrm{M} \mathrm{Na}_{2} \mathrm{SO}_{4}$ aqueous solution, adjusted to $\mathrm{pH} 12$ by adding $\mathrm{NaOH}$. The electrolyte was bubbled with $\mathrm{N}_{2}$ gas for 30 min before each experiment and maintained under an $\mathrm{N}_{2}$ atmosphere during the experiments. Linear sweep voltammetry (LSV), cyclic voltammetry (CV) and chronoamperograms (CA) were performed using an EDAQ466 potentiostat. Where applicable, the sample was illuminated with a SoLux daylight MR16 halogen light bulb (12 V, $50 \mathrm{~W}, 24^{\circ} ; 0.25$ sun intensity) with a stable output range of 275 - $750 \mathrm{~nm}$. The light was placed $10 \mathrm{~cm}$ from the working electrode. A Thorlabs visible-light bandpass filter (315-710 nm) was placed $1.5 \mathrm{~cm}$ in front of the light source. The bandpass filter removed any heat (infra-red wavelengths) generated by the light source. EIS studies were conducted under the same conditions as the amperometric study (0.8 V vs Ag/AgCl; pH 12), with the same light source, with frequencies between $0.1 \mathrm{~Hz}$ and $150 \mathrm{KHz}$ applied. 
4.5 Gas Analysis Studies. Photocurrent testing of high performing PEDOT/Nano-Ni/rGO samples on FTO glass with simultaneous gas analysis was performed using a custom-built apparatus. The apparatus, which is depicted in Figure S1 (Supplementary Material), comprised of a fully-enclosed electrochemical cell containing two sealed, half-cells whose electrolytes were separated only by a Nafion 117 proton exchange membrane $(5 \mathrm{~cm} \mathrm{x} 4 \mathrm{~cm})$. The one half cell contained the working electrode sample and a Ag/AgCl reference electrode. The other half-cell contained the Pt mesh counter electrode. One wall of the former half-cell was a quartz sheet. Illumination from the above light source was passed through the quartz sheet onto the working electrode. The incident light was filtered with the above bandpass filter. The electrodes were connected to a CHI potentiostat. The gas outlets for the working and counter electrode half cells were connected with gas-tight polymer and stainless steel tubing to sample loops connected to a dedicated Shimadzu GC-8A gas chromatograph.

After fitting the electrodes, both half cells were filled with electrolyte. The electrolyte in each half cell was then separately purged with Ar gas overnight to remove all air inside the cell (without a voltage or light-illumination being applied to the cell). Thereafter, the Ar passing through each half cell was sampled, injected and analysed using the attached gas chromatograph, with the results plotted over 30 min of elution time. The analyses verified that there was no gas other than Ar detected in the gas streams passing through each half-cell. The Ar gas, which was continuously bubbled through the electrolyte throughout the photocurrent experiment, acted as a carrier gas for the connected GC.

A voltage bias of $0.8 \mathrm{~V}$ (vs. $\mathrm{Ag} / \mathrm{AgCl}$ ) with and without light-illumination was then applied to the cell, whereafter the carrier gas was tested as described above, for electrocatalysis product gases using the GC. The identities of the gases in the carrier Ar were determined by their 
retention times. Their relative proportions were determined by integrating the area under their respective peaks. GC testing of this type, after illumination and biasing, provided a well-founded estimate of the proportions of gases produced by the films.

\section{ASSOCIATED CONTENT}

\section{Supporting Information}

Supporting Information is available free of charge on the ACS Publications website at DOI:....

Photographs and schematics of the cell used in the gas detection studies; GC Traces of the gas collected.

\section{AUTHOR INFORMATION}

\section{Corresponding Author}

*Email: $\underline{\text { Swiegers@uow.edu.au }}$

\section{ORCID}

G. F. Swiegers 0000-0002-4713-6090

Notes

The authors declare no competing financial interests 
MA thanks the Government of Iraq for a PhD scholarship. The authors thank A/Prof Attila Mozer of the University of Wollongong for use of a GC gas analyser. The authors acknowledge the Australian National Fabrication Facility (ANFF) Materials Node for equipment use and $\mathrm{Mr}$ Adam Taylor for design and printing of the custom-built apparatus. Support from the Australian Research Council Centre of Excellence Scheme (Project Number CE140100012) is gratefully acknowledged. The authors acknowledge use of facilities and the assistance of Tony Romeo within the University of Wollongong Electron Microscopy Centre. This research used equipment funded by the Australian Research Council (ARC) - Linkage, Infrastructure, Equipment and Facilities (LIEF) grant LE160100063 located at the University of Wollongong Electron Microscopy Centre.

\section{REFERENCES}

(1) Alsultan, M.; Ranjbar, A.; Swiegers, G. F.; Wallace, G. G.; Balakrishnan, S.; Huang, J. In Application of Conducting Polymers in Solar Water-Splitting Catalysis In Industrial Applications for Intelligent Polymers and Coatings; Hosseini, M.; Makhlouf, A. S., Eds.; Springer International Publishing: Switzerland, 2016; Chapter 11, pp 223-251, and references therein.

(2) Chen, J.; Wagner, P.; Tong, L.; Wallace, G.; Officer, D.; Swiegers, G. A Porphyrindoped Polymer Catalyzes Selective, Light-assisted Water Oxidation in Seawater. Angew. Chem. Int. Ed. 2012, 51, 1907-1910.

(3) Chen, J.; Wagner, P.; Tong, L.; Boskovic, D.; Zhang, W.; Officer, D. L.; Wallace, G. G.; Swiegers, G. F. A Light-assisted, Polymeric Water Oxidation Catalyst that Selectively Oxidizes Seawater with a Low Onset Potential. Chem. Sci. 2013, 4, 2797-2803. 
(4) Fabbri, E.; Schmidt, T.; Fabbri, E.; Habereder, A.; Waltar, K.; Koetz, R.; Schmidt, T. Developments and Perspectives of Oxide-based Catalysts for the Oxygen Evolution Reaction. Catal. Sci. Tech. 2014, 11, 3800-3821.

(5) Kuo, D.; Schlom, D.; Suntivich, J.; Kawasaki, J.; Nelson, J.; Shen, K.; Kloppenburg, J.; Hautier, G. Influence of Surface Adsorption on the Oxygen Evolution Reaction on $\mathrm{IrO}_{2}(110)$. J. Am. Chem. Soc. 2017, 139, 3473-3479.

(6) Jeffrey C. S. W.; Chao-Wei, H.; Chi-Hung, L. Hydrogen Production from Semiconductor-based Photocatalysis via Water Splitting. Catalysis 2012, 2, 490-516.

(7) Pijpers, J. H.; Winkler, M. T.; Surendranath, Y.; Buonassisi, T.; Nocera, D. G. Lightinduced Water Oxidation at Silicon Electrodes Functionalized with a Cobalt OxygenEvolving Catalyst. Proc. Natl. Acad. Sc. USA 2011, 108, 10056-10061.

(8) Jafari, T.; Moharreri, E.; Amin, A. S.; Miao, R.; Song, W.; Suib, S. L. Photocatalytic Water Splitting - The Untamed Dream: A Review of Recent Advances. Molecules 2016, 21, article number 900.

(9) Li, X.; Yu, J.; Low, J.; Fang, Y.; Xiao, J.; Chen, X. Engineering Heterogeneous Semiconductors for Solar Water Splitting. J. Mat. Chem. A. 2015, 3, 2485-2534.

(10) Jing, T.; Dai, Y.; Ma, X.; Wei, W.; Huang, B. Electronic Structure and Photocatalytic Water-Splitting Properties of $\mathrm{Ag}_{2} \mathrm{ZnSn}\left(\mathrm{S}_{1-\mathrm{x}} \mathrm{Se}_{\mathrm{x}}\right)_{4}$. J. Phys. Chem. C. 2015, 119, 27900-27908.

(11) Hesketh, M.; Misra, D. Conducting Polymers and their Applications. Electrochem. Soc. Interface, 2012, 21, 61 and articles in the issue. 
(12) Gustafson, M. P.; Matsumoto, K.; MacFarlane, D. R.; Winther-Jensen, B. An Investigation of the Properties of Conducting Polymer Alloys for Water Oxidation. Electrochim. Acta 2014, 122, 166-172.

(13) Li, X.; Lu, W.; Dong, W.; Chen, Q.; Wu, D.; Zhou, W.; Chen, L. Si/PEDOT Hybrid Core/shell Nanowire Arrays as Photoelectrodes for Photoelectrochemical WaterSplitting. Nanoscale 2013, 5, 5257-5261.

(14) Duan, C.; Wang, H.; Ou, X.; Li, F.; Zhang, X. Efficient Visible Light Photocatalyst Fabricated by Depositing Plasmonic Ag Nanoparticles on Conductive PolymerProtected Si Nanowire Arrays for Photoelectrochemical Hydrogen Generation. ACS Appl. Mater. Interfaces 2014, 6, 9742-9750.

(15) Chowdhury, A.; Agnihotria, N.; Sen, P.; De, A. Conducting $\mathrm{CoMn}_{2} \mathrm{O}_{4}$ - PEDOT Nanocomposites as Catalyst in Oxygen Reduction Reaction. Electrochim. Acta 2014, 8187.

(16) Haubner, K.; Murawski, J.; Olk, P.; Eng, L.; Ziegler, C.; Adolphi, B.; Jaehne, E. The Route to Functional Graphene Oxide. ChemPhysChem, 2010, 11, 2131-2139.

(17) Wang, G.; Wang, B.; Park, J.; Yang, J.; Shen, X.; Yao, J. Synthesis of Enhanced Hydrophilic and Hydrophobic Graphene Oxide Nanosheets by a Solvothermal Method. Carbon 2009, 47, 68-72.

(18) Si, Y.; Samulski, E. T. Synthesis of Water Soluble Graphene. Nano Lett. 2008, 8, 1679-1682.

(19) Sharma, D.; Kanchi, S.; Sabela, M. I.; Bisetty, K. Insight into the Biosensing of Graphene Oxide: Present and Future Prospects. Arab. J. Chem., 2016, 9, 238-261. 
(20) Mohan, V. B.; Brown, R.; Jayaraman, K.; Bhattacharyya, D. Characterization of Reduced Graphene Oxide: Effects of Reduction Variables on Electrical Conductivity. Mater. Sci. Eng. B 2015, 193, 49-60.

(21) Kim, K. H.; Yang, M.; Cho, K. M.; Jun, Y. S.; Lee, S. B; Jung, H. T. High Quality Reduced Graphene Oxide through Repairing with Multi-layered Graphene Ball Nanostructures. Sci. Rep. 2013, 3, article number: 3251.

(22) Liang, Y.; Li, Y.; Wang, H.; Zhou, J.; Wang, J; Regier, T.; Dai, H. $\mathrm{Co}_{3} \mathrm{O}_{4}$ Nanocrystals on Graphene as a Synergistic Catalyst for Oxygen Reduction Reaction. Nature Mat. 2011, 10, 780-786.

(23) See, for example: Liu, Q.; Jin, J.; Zhang, J. $\mathrm{NiCo}_{2} \mathrm{~S}_{4} @$ graphene as a Bifunctional Electrocatalyst for Oxygen Reduction and Evolution Reactions. ACS Appl. Mater. Interfaces 2013, 5, 5002-5008

(24) See, for example: Long, X.; Li, J.; Xiao, S.; Yan, K.; Wang, Z.; Chen, H.; Yang, S. A Strongly Coupled Graphene and FeNi Double Hydroxide Hybrid as an Excellent Electrocatalyst for the Oxygen Evolution Reaction Angew. Chem. Int. Ed. 2014, 53, 7584-7588.

(25) See, for example: Gao, M.-R.; Cao, X.; Gao, Q.; Xu, Y.-F.; Zheng, Y.-R.; Jiang, J.; Yu, S.-H. Nitrogen-doped Graphene Supported $\mathrm{CoSe}_{2}$ Nanobelt Composite Catalyst for Efficient Water Oxidation. ACS Nano 2014, 8, 3970-3978.

(26) See, for example: Ng, Y. H.; Iwase, A.; Kudo, A.; Amal, R. Reducing Graphene Oxide on a Visible-light BiVO4 Photocatalyst for Enhanced Photoelectrochemical Water Splitting J. Phys. Chem. Lett. 2010, 1, 2607-2612. 
(27) See, for example: Guo, J.; Li, Y.; Zhu, S.; Chen, Z.; Liu, Q.; Zhang, D.; Moon, W.; Song, D. Synthesis of $\mathrm{WO}_{3} @$ Graphene Composite for Enhanced Photocatalytic Oxygen Evolution from Water. RSC Adv. 2012, 2, 1356-1363.

(28) See, for example: Quintana, M.; López, A. M.; Rapino, S.; Toma, F. M.; Iurlo, M.; Carraro, M.; Sartorel, A.; Maccato, C.; Ke, X.; Bittencourt, C.; Da Ros, T.; Van Tendeloo, G.; Marcaccio, M.; Paolucci, F.; Prato, M.; Bonchio, M. Knitting the Catalytic Pattern of Artificial Photosynthesis to a Hybrid Graphene Nanotexture. ACS Nano 2013, 7, 811-817.

(29) Agegnehu, A.; Pan, C.-J.; Rick, J.; Hwang, B.-J.; Su, W.-N.; Lee, J. Enhanced Hydrogen Generation by Cocatalytic Ni and NiO Nanoparticles Loaded on Graphene Oxide Sheets J. Mat. Chem. 2012, 22, 13849-13854.

(30) For other examples of synergistic effects, see: Xu, H.; Song, P.; Wang, J.; Gao, F.; Zhang, Y.; Guo, J.; Du, Y.; Di, J. Visible-Light-Improved Catalytic Performance for Methanol Oxidation on Plasmonic PtAu Dendrites. ChemElectroChem. 2018, 5, 1-7.

(31) For other examples of synergistic effects, see: Xu, H; Yan, B.; Wang, J.; Zhang, K.; Li, S.; Xiong, Z.; Wang, C.; Shiraishi, Y.; Du, Y.; Yang, P. Self-supported Porous 2D AuCu Triangular Nanoprisms as Model Electrocatalysts for Ethylene Glycol and Glycerol Oxidation. J. Mater. Chem. A 2017, 5, 15932-15939.

(32) For other examples of synergistic effects, see: Xu, H.; Song, P.; Yan, B.; Wang, J.; Guo, J.; Du, Y. Surface-Plasmon-Enhanced Photo-electrocatalytic Ethylene Glycol Oxidation Based on Highly Open AuAg Nanobowls. ACS Sustainable Chem. Eng. 2018, 6, 4138-4146. 
(33) Lang, G. G.; Ujvari, M.; Vesztergom, S.; Kondratiev, V.; Gubicza, J.; Szekeres, K. J. The Electrochemical Degradation of Poly(3,4-ethylenedioxythiophene) Films Electrodeposited from Aqueous Solutions. Zeit. Physalk. Chem. Int. J. Research Phys. Chem. Chem. Phys. 2016, 230, 1281-1302.

(34) Z. Wei, J. Ma, W. Feng, J. Dai, Q. Wang, T. Xia, P. Yan. Investigation of the Lattice Expansion for Ni nanoparticles. Mater. Charact. 2007, 58, 1019-1024.

(35) J. Lu, Y. Li, S. Li, S. Jiang. Self-assembled Platinum Nanoparticles on Sulfonic acidgrafted Graphene as Effective Electrocatalysts for Methanol Oxidation in Direct Methanol Fuel Cells. Sci. Rep. 2016, 6, Article no. 21530.

D. Mhamane, M. Kim, H. Kim, D. Ruan, K. Kim, V. Aravindan, M. Srinivasan, K. Roh, S. Lee. Silica-assisted Bottom-up Synthesis of Graphene-like High Surface Area Carbon for Highly Efficient Ultracapacitor and Li-ion Hybrid Capacitor Applications. J. Mater. Chem. A 2016, 4, 5578-5591.

(37) K. Yuan, M. Forster, U. Scherf, Y. Xu, M. Que, Y. Chen, J. Uihlein, T. Chassé, G. Brunklaus, L. Shi, T. Pichler, R. Heiderhoff, T. Riedl. Straightforward Generation of Pillared, Microporous Graphene Frameworks for Use in Supercapacitors. Adv. Mat. 2015, 27, 6714-6721.

(38) A. Shaikh, S. Parida, S. Böhm. One Step Eco-friendly Synthesis of Ag-reduced Graphene Oxide Nanocomposite by Phytoreduction for Sensitive Nitrite Determination. RSC Adv. 2016, 6, 100383-100391.

(39) P. Benjwal, P. Chamoli, K. Kar, M. Kumar. Enhanced Photocatalytic Degradation of Methylene Blue and Adsorption of Arsenic(III) by Reduced Graphene Oxide (rGO)Metal Oxide $\left(\mathrm{TiO}_{2} / \mathrm{Fe}_{3} \mathrm{O}_{4}\right)$ Based Nanocomposites. RSC Adv. 2015, 5, 73249-73260. 
(40) Li, Z.; Huang, X.; Zhang, X.; Zhang, L.; Lin, S. The Synergistic Effect of Graphene and polyoxometalates enhanced electrocatalytic activities of Pt- $\left\{\mathrm{PEI}-\mathrm{GNs} /\left[\mathrm{PMo}_{12} \mathrm{O}_{40}\right]^{3-}\right\}_{\mathrm{n}}$ composite films regarding methanol oxidation. J. Mater. Chem. 2012, 22, 23602-23607.

(41) Huang, X.; Li, Z.; Zhang, X.; He, X.; Lin, S. Preparation of Pt/\{PDDA-GN/PSS-GN\}n multilayer films and their electrocatalytic activity regarding methanol oxidation. $J$. Colloid Interfac. Sci. 2013, 393, 300-305.

(42) Li, Z.; Ye, L.; Lei, F.; Wang, Y.; Xu, S.; Lin, S. Enhanced electro-photo synergistic catalysis of $\mathrm{Pt}(\mathrm{Pd}) / \mathrm{ZnO} /$ graphene composite for methanol oxidation under visible light irradiation. Electrochim. Acta 2016, 188, 450-460.

(43) M. Wang, M. Zhou, L. Zhu, Q. Li, C. Jiang. Enhanced Polymer Solar Cells Efficiency by Surface Coating of the PEDOT: PSS with Polar Solvent. Solar Energy, 2016, $129,175-183$.

(44) T. Ji, L. Tan, X., Hu, Y. Dai, Y. Chen. A Comprehensive Study of Sulfonated Carbon Materials as Conductive Composites for Polymer Solar Cells. Phys. Chem. Chem. Phys. 2015, 17, 4137-4145.

(45) A. Kanwat, J. Jang. Extremely Stable Organic Photovoltaic Incorporated with $\mathrm{WO}_{\mathrm{x}}$ doped PEDOT:PSS Anode Buffer Layer. J. Mater. Chem. C 2014, 2, 901-907.

(46) A. Bagri, V. Shenoy, C. Mattevi, M. Chhowalla, M. Acik, Y. Chabal. Structural Evolution during the Reduction of Chemically Derived Graphene Oxide. Nature Chem. 2010, 2, 581-587.

(47) V. Sridhar, I. Lee, H. Chun, H. Park. Hydroquinone as a Single Precursor for Concurrent Reduction and Growth of Carbon Nanotubes on Graphene Oxide. RSC Adv. 2015, 5, 68270-68275. 
(48) Z. Xing, Z. Ju, Y. Zhao, J. Wan, Y. Zhu, Y. Qiang, Y. Qian. One-pot Hydrothermal Synthesis of Nitrogen-doped Graphene as High-performance Anode Materials for Lithium Ion Batteries. Sci. Rep. 2016, 6, article no. 26146.

(49) H. Yu, B. Zhang, C. Bulin, R. Li, R. Xing. High-efficient Synthesis of Graphene Oxide Based on Improved Hummers Method. Sci. Rep. 2016, 6. Article no. 36143.

(50) J. Zhang, D. Zeng, J. Wu, K. Xu, Q. Zhu, G. Zhang, C. Xie, S. Zhao. Room Temperature $\mathrm{NO}_{2}$ sensing: what advantage does the rGO-NiO Nanocomposite have over Pristine NiO? Phys. Chem. Chem. Phys. 2015, 17, 14903-14911.

(51) Kumar, D. R.; Manoj, D.; Santhanalakshmi, J. Electrostatic Fabrication of Oleylamine-capped Nickel Oxide Nanoparticles Anchored Multiwall Carbon Nanotube Nanocomposite: A Robust Electrochemical determination of Riboflavin at Nanomolar Levels. Anal. Methods 2014, 6, 1011-1020.

(52) George, G.; Anandhan, S. Synthesis and Characterization of Nickel Oxide Nanofibre webs with Alcohol Sensing Characteristics. RSC Adv. 2014, 4, 62009-62020.

(53) Brug, G. J.; van den Eeden, A. L. G.; Sluyters-Rehbach, M.; Sluyters, J. H. The Analysis of Electrode Impedances Complicated by the Presence of a Constant Phase Element. $J$. Electroanal. Chem. 1984, 176, 275-295.

(54) Shimizu, K.; Boily, J.; Lasia, A. Electrochemical Impedance Study of the Hematite/water Interface. Langmuir 2012, 28, 7914-7920.

(55) Swierk, J. R.; Klaus, S.; Trotochaud, L.; Bell, A. T.; Tilley, T. D. Electrochemical Study of the Energetics of the Oxygen Evolution Reaction at Nickel Iron (Oxy)Hydroxide Catalysts. J. Phys. Chem. C 2015, 119, 19022-19029. 
(56) Damjanovic, A.; Deyt, A.; Bockris, J. O’M. Kinetics of Oxygen Evolution and Dissolution on Platinum Electrodes. Electrochim. Acta 1966, 11, 791-799.

(57) Esrafilzadeh, D.; Jalili, R.; Stewart, E.; Razal, J.; Moulton, S.; Wallace, G. G.; Aboutalebi, S. High-Performance Multifunctional Graphene-PLGA Fibers: Toward Biomimetic and Conducting 3D Scaffolds. Adv. Funct. Mater. 2016, 26, 3105-3117.

(58) Jalili, R.; Esrafilzadeh, D.; Shepherd, R.; Chen, J.; Razal, J.; Wallace, G. G.; Aboutalebi, S.; Aminorroaya-Yamini, S.; Konstantinov, K.; Minett, A. Scalable One-step Wetspinning of Graphene Fibers and Yarns from Liquid Crystalline Dispersions of Graphene Oxide: Towards Multifunctional Textiles Adv. Funct. Mater. 2013, 23, 5345-5354.

(59) Jalili, R.; Aboutalebi, S. H.; Esrafilzadeh, D.; Konstantinov, K.; Razal, J. M.; Moulton, S. E.; Wallace, G. G. Formation and Processability of Liquid Crystalline Dispersions of Graphene Oxide. Mater. Horiz. 2014, 1, 87-91.

(60) Naficy, S.; Jalili, R.; Aboutalebi, S.; Gorkin, R.; Konstantinov, K.; Innis, P.; Spinks, G.; Poulin, P.; Wallace, G. G. Graphene Oxide Dispersions: Tuning Rheology to enable Fabrication. Mater. Horiz. 2014, 1, 326-331.

(61) Gambhir, S.; Jalili, R.; Officer, D. L.; Wallace, G. G. Chemically Converted Graphene: Scalable Chemistries to enable Processing and Fabrication. NPG Asia Mater. 2015, 7, e186-1-e186-15.

(62) Jalili, R.; Esrafilzadeh, D.; Moulton, S.; Razal, J.; Wallace, G. G.; Aboutalebi, S.; Konstantinov, K. Organic Solvent-based Graphene Oxide Liquid Crystals: A Facile Route toward the Next Generation of Self-assembled Layer-by-layer Multifunctional 3D Architectures ACS Nano 2013, 7, 3981-3990. 
FOR TABLE OF CONTENTS (TOC) ONLY

\section{TOC Graphic}

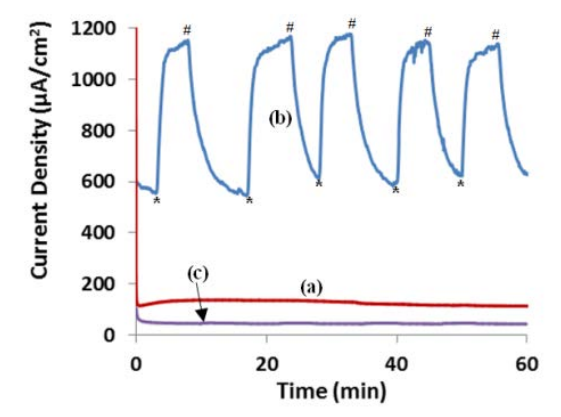

\section{TOC Synopsis}

The conditions under which thin-film conducting polymer supports may synergistically amplify catalysis has been investigated. A composite conducting polymer film has been developed that, when overcoated on a bare Pt electrode, amplifies its catalytic performance by an order of magnitude. Studies suggested that the amplification was created by a synergistic matching of the connectivity, conductivity, and catalytic capacity of the film. 